\title{
1 Ionospheric Detection of Natural Hazards
}

2

3 Elvira Astafyeva

4

5 Institut de Physique du Globe de Paris (IPGP), Université de Paris, CNRS UMR 7154, 35 Rue

6 Hélène Brion, 75013 Paris, e-mail: astafyeva@ipgp.fr

7

8

9 Key-points:

10

11 - Natural Hazards can generate perturbations in the atmosphere and ionosphere via

12 acoustic and gravity waves

13

14 - From ionospheric observations, it is possible to detect natural hazards and to determine

15 their source parameters

16

17 - The review presents recent advances in detection of ionospheric disturbances generated 18 by earthquakes, tsunamis and volcanic eruptions 

0

\section{Abstract}

Natural Hazards (NH), such as earthquakes, tsunamis, volcanic eruptions, and severe tropospheric weather events, generate acoustic and gravity waves that propagate upward and cause perturbations in the atmosphere and ionosphere. The first NH-related ionospheric disturbances were detected after the great 1964 Alaskan earthquake by ionosondes and Doppler sounders. Since then, many other observations confirmed the responsiveness of the ionosphere to natural hazards. Within the last two decades, outstanding progress has been made in this area owing to the development of networks of ground-based dual-frequency Global Navigation Satellite Systems (GNSS) receivers. The use of GNSS-sounding has substantially enlarged our knowledge about the Solid Earth/ocean/atmosphere/ionosphere coupling and NH-related ionospheric disturbances and their main features. Moreover, recent results have demonstrated that it is possible to localize NH from their ionospheric signatures, and also, if/when applicable, - to obtain the information about the NH source (i.e., the source location and extension, and the source onset time). Although all these results were obtained in retrospective studies, they have opened an exciting possibility for future ionosphere-based detection and monitoring of $\mathrm{NH}$ in near-real time.

This article reviews the recent developments in the area of ionospheric detection of earthquakes, tsunamis and volcanic eruptions, and it discusses the future perspectives for this novel discipline.

\section{Plain Language Summary}

The ionosphere is the ionized region of the Earth's atmosphere that is located between $\sim 60$ to $\sim 1000 \mathrm{~km}$ of altitude. The ionosphere is largely impacted by the solar and magnetic activities, as well as by the neutral atmosphere. Besides these large-scale and global processes influencing from above, the ionosphere can be more "locally" perturbed from below by geophysical phenomena (e.g., earthquakes, tsunamis, volcanic eruptions, severe tropospheric weather events), and by man-made events (e.g., explosions, rocket and missile launches, mine blasts). From below, the disturbances arrive in the ionosphere as acoustic and gravity waves. Upon their upward propagation, these waves grow in amplitude up to a million times owing to the exponential decrease of the atmospheric density with height. Consequently, the acoustic and gravity waves generated at the Earth's surface may provoke significant perturbations in the upper atmosphere and ionosphere. In the ionosphere, the perturbations can be detected by ionospheric sounding tools, such as, Global Navigation Satellite System 
(GNSS) receivers, ionosondes, airglow cameras, etc.

\section{Introduction}

Natural Hazards ( $\mathrm{NH}$ ) are naturally occurring phenomena of geological, hydrological or meteorological origin that might have a negative impact on humans or on the environment. Every year, NH affect and take the lives of thousands of people. Some NH of meteorological origin (hurricanes, tornadoes, and floods) can be forecasted and monitored in near real-time. However, most geological NH (earthquakes, volcanic eruptions, landslides and tsunamis) remain difficult or even impossible to predict. Therefore, their rapid and timely detection becomes the only way to prevent or to reduce the human loss. To detect these NH in near-real time, many different multi-instrumental approaches and methods are already in use throughout the world. For instance, the Seismic Monitor by the Incorporated Research Institutions for Seismology (IRIS, http://ds.iris.edu/seismon/) allows users to monitor global earthquakes in real time. For tsunami warnings and monitoring, there exist several regional and global systems: the U.S. Tsunami Warning System (https://www.tsunami.gov/), the Japan warning system by the Japan Meteorological Agency (http://www.jma.go.jp/en/tsunami/), the German-Indonesian Tsunami Early Warning System for the Indian Ocean (https://www.gitews.org/; Falck et al., 2010), etc. These systems largely rely on "classic" geophysical datasets. However, despite numerous efforts, the classic methods still fail to correctly estimate the magnitude of large earthquakes (Mw>8) in real-time and, therefore, they also fail to correctly estimate the tsunami potential. In response to this need, it has recently been suggested that the ionosphere-based technique could, in future, present a novel approach for NH-detection in near-real time (e.g., Savastano et al., 2017).

Huang et al. (2019) have recently provided an extended review on ionospheric detection of explosive events. The current review article is exclusively targeted at ionospheric detection of such natural hazards as earthquakes, tsunamis and volcanic eruptions. After a detailed overview of the recent developments and main challenges in this branch of geophysics, this article discusses future perspectives for this novel discipline.

\subsection{Ionosphere, a natural sensor for Geophysics}

The ionosphere is a part of the upper atmosphere that extends from $\sim 60$ to $\sim 800 \mathrm{~km}$ of altitude, where the concentration of charged particles (i.e., free electrons and ions) is 
increased. The total mass of the ionosphere is $10^{12}-10^{13}$ times smaller than the mass of the neutral atmosphere, and, at all altitudes, charged particles can be considered as a minor constituent in the particle mix.

The ionosphere is a highly irregular and variable medium; its state is determined by several competing large-scale impacts [Hargreaves, 1992]. First of all, the concentration of charged particles varies depending on the level of solar activity. Second, the ionization also depends on the day/night conditions, on the season and on latitudes (solar zenith angle dependence). Third, the electron density distribution is dependent on the altitude, defining the ionospheric layers: D (60-90 km of altitude), E (90-120 km), F (120-800 km). The ionization maximum (hmF2) is reached within the F-layer, at the altitude of $\sim 250-400 \mathrm{~km}$. Fourth, the ionosphere is tightly coupled with the neutral upper atmosphere (thermosphere). The thermosphere serves as a supplier of particles that can be ionized, it determines the speed of ionization and regulates the recombination processes. Fifth, the ionosphere can be strongly perturbed by disturbances in the geomagnetic field, such as geomagnetic storms and substorms. In addition, the magnetic field plays an important role in the propagation of plasma perturbations. The ionized particles are not free to move horizontally, as they are confined by the earth's magnetic field. As a result, any movement of the neutral air in the meridional direction will blow ionization along the magnetic field.

All these features impact the strength of the Solid-Earth/atmosphere/ionosphere coupling, as well as the propagation of NH-related disturbances in the ionosphere. The perturbations are initially generated on the ground/ocean surface as acoustic and gravity waves.

\subsection{Acoustic and gravity waves and their propagation in the atmosphere}

Impulsive forcing from the Earth's surface occurring due to earthquakes, explosions, volcanic eruptions, tsunamis, etc., trigger atmospheric pressure waves. Depending on their frequencies, these atmospheric waves can be distinguished as acoustic and gravity waves (Figure 1; Blanc, 1985; Huang et al., 2019). The acoustic waves are characterized by frequencies higher than the acoustic cut-off frequency $\left(\omega_{a}\right)$, i.e. higher than $\sim 3.3 \mathrm{mHz}$. The acoustic waves are longitudinal waves in which particle moves in the direction of the wave propagation. The force restoring a displaced particle towards its original position is the change of pressure associated with the compression of the medium [Hargreaves, 1992]. Therefore, acoustic waves travelling through a gas disturb the equilibrium state by 
compressions and rarefactions [Zel'dovich and Raizer, 2002]. The acoustic waves propagate at the speed of sound that is equal to $\sim 330 \mathrm{~m} / \mathrm{s}$ at the surface, and grows up to $800-1000 \mathrm{~m} / \mathrm{s}$ at the ionospheric altitude of 250-300 km. Therefore, it only takes $\sim 8-9$ minutes for the acoustic waves to reach the ionosphere.

When the wavelength of a wave increases, gravity starts to act on the mass displacement and becomes the restoring force [Hargreaves, 1992; Fritts and Alexander, 2003; 2012]. Gravity waves are characterized by frequencies below the Brunt-Väisälä frequency $\omega_{b}$ (i.e., typically $\sim 2.9 \mathrm{mHz}$ in the lower atmosphere). Because of the gravity action, the gravity waves cannot propagate upward vertically but do so obliquely; their velocity is much lower than the sound speed, and their group and phase vertical velocities are opposite-directed [Hines, 1960; Huang et al., 2019]. The gravity waves reach the ionospheric altitudes in 45-60 minutes from the time of their generation on the ground/ocean surface.

The sources of the acoustic waves are: earthquakes, Rayleigh surface waves, explosions, including volcanic and nuclear explosions, mine blasts, rocket launches, etc. [e.g., Blanc, 1985; Calais \& Minster 1995; Calais et al., 1998; Pokhotelov et al., 1995; Afraimovich et al., 2001; 2013; Heki and Ping, 2005]. In turn, gravity waves are generated by tsunamis propagating on the ocean surface, by volcanic eruptions, by severe tropospheric events, such as tropical storms, typhoons, hurricanes, [e.g., Hines, 1960; Artru et al., 2004; Fritts and Alexander, 2003; 2012; Rolland et al., 2010; Occhipinti et al., 2013; Dautermann et al., 2009a,b; Nishioka et al., 2013; Chou et al., 2017].

The propagation and evolution of the acoustic and gravity waves in the atmosphere is greatly affected by the propagation medium and its properties. The exponential decrease of the atmospheric density with the altitude leads to the growth of both acoustic and gravity waves upon their upward propagation. The wave's amplitude is proportional to the atmospheric density; however, in accordance with the energy conservation law, the amplitude of the acoustic and gravity waves increases in order to maintain constant energy flux [Hines, 1960]. The resulting amplification factor reaches $10^{4}$ at $\sim 150 \mathrm{~km}$ of altitude (lower atmosphere) and $10^{5-10^{6}}$ at $350-400 \mathrm{~km}$ (upper atmosphere and ionosphere) [Blanc et al., 2010; Lognonné et al., 2006].

Competing with the amplification, damping effects occur because of the wave energy dissipation due to molecular viscosity and thermal conductivity [Hines, 1960; Blanc, 1985]. The rate of energy dissipation is proportional to the kinematic viscosity, which in turn is almost inversely proportional to the atmospheric density. Consequently, the effect of energy dissipation becomes more important at greater altitudes. Further, the dissipation tends to 
stronger affect higher-frequency waves, and these waves are removed as the certain altitudes are reached [Hines, 1960; Huang et al., 2019]. Thus, the wave amplitude reaches the maximum before vanishing at the altitudes of $\sim 110 \mathrm{~km}$ for periods of $1 \mathrm{~s}$ and $\sim 160 \mathrm{~km}$ for periods of 10s [Blanc et al., 2010]. The damping is also affected by non-linearity, propagation speed dispersion as well as by the magnetic field [Naugolnykh and Ostrovsky, 1998].

It should be noted that powerful sources such as explosions and large earthquakes can generate intense pressure waves that transform into shock waves upon their propagation in the atmosphere [e.g., Pokhotelov et al., 1995; Zettergen et al., 2017]. These waves therefore propagate at velocities exceeding the speed of sound.

\subsection{Wave interaction with ionospheric plasma and magnetic field}

When acoustic and gravity waves reach the ionospheric altitudes, they induce fluctuations in the ionospheric electron density through dynamical and photochemical processes. The ionospheric photochemical balance can be significantly altered by neutral waves at lower altitudes (below $250 \mathrm{~km}$ ), i.e. in weakly ionized medium [George and Hooke, 1970]. In regions with higher electron concentration (typically above $250 \mathrm{~km}$ of altitude), we can assume that the atmospheric wave interacts with the ionospheric plasma only through momentum transfer by collisions of neutrals with electrons and ions, which respond by moving along the magnetic field direction. The velocity of the charged particles follows approximately $V=V n^{*} \cos (\alpha)$, where $V n$ is the neutral particle velocity and $\alpha$ the angle between the acoustic wave propagation direction and the magnetic field line.

It should be noted that the neutral waves generate not only perturbations in the electron density, but also perturbations in the electric and magnetic fields, because of the interaction of charged particles through electromagnetic forces to maintain the ionosphere electrically neutral [e.g., Occhipinti et al., 2008; Kherani et al., 2008; 2012; Zettergren and Snively, 2015].

The fluctuations of the ionospheric plasma provoked by acoustic and gravity waves are commonly referred to as traveling ionospheric disturbances (TIDs).

Numerous instruments can be used for studying the ionosphere dynamics and for detection of TIDs. Global Navigation Satellite Systems (GNSS) is the main instrument used for observations of NH-related TIDs.

\subsection{Global Navigation Satellite Systems (GNSS) for Ionospheric Sounding}


GNSS offer a powerful and accessible tool allowing the monitoring of the ionosphere.

191 Due to the dispersive nature of the ionosphere, signals from dual-frequency GNSS receivers make it possible to measure the total electron content (TEC) - the electron density integrated along the raypath from a satellite to a receiver (Hoffmann-Wellenhof et al., 2008):

$$
T E C=\int_{\text {raypath }} N(d \vec{r}) d \vec{r}
$$

194

As of today, operational GNSS comprise the American Global Positioning System (GPS), Russia's GLONASS, the European Union's Galileo, China's BeiDou, Japan's Quasi-Zenith Satellite System (QZSS), the Indian Regional Navigation Satellite System (IRNSS, or NAVIC). From GNSS signals transmitted at two distinct carrier-frequencies, $f_{1}$ and $f_{2}$, it is possible to calculate the differential (relative) slant TEC:

$$
T E C=\frac{1}{A} \cdot \frac{f_{1}^{2} f_{2}^{2}}{f_{1}^{2}-f_{2}^{2}}\left(L_{1} \lambda_{1}-L_{2} \lambda_{2}+\text { const }+n L\right)
$$

where $A=40.308 \mathrm{~m}^{3} / \mathrm{s}^{2}, L_{1} \lambda_{1}$ and $L_{2} \lambda_{2}$ are additional paths of the signal caused by the phase delay in the ionosphere, const is unknown initial phase path, caused by the unknown number of total phase rotations along the raypath and $n L$ are errors in determining the phase path.

TEC is measured in TEC units (TECU) which is equal to $10^{16}$ electrons $/ \mathrm{m}^{2}$. The accuracy of the differential TEC estimation from phase measurements is about 0.01-0.02 TECU (e.g., Coster et al., 2013).

In order to normalize the TEC amplitude and to avoid effects of low elevation angles, the slant TEC can be converted to vertical TEC (VTEC) by applying the following formula known as mapping function:

$$
V T E C=S T E C * \cos \left[\arcsin \left(\frac{R_{Z}}{R_{z}+H_{\text {ion }}} \cos \theta_{s}\right)\right]
$$

where $\mathrm{Rz}$ is the Earth's radius, $H_{\text {ion }}$ is the altitude of the ionospheric thin shell, $\theta s$ is the elevation angle.

Knowing the positions of GNSS satellites and those of ground-based GNSS-receivers, one can estimate the coordinates of TEC perturbations. Assuming that the ionosphere is a thin shell layer located at the altitude $H_{\text {ion }}$ (Figure 2), the intersection point between the $H_{\text {ion }}$ and line-of-sight (LOS) between a satellite and a receiver is called ionospheric piercing point (IPP). The IPP projection onto the Earth's surface is called a sub-ionospheric point (SIP). 
218 These IPP and SIP allow tracking ionospheric TEC perturbations observed by the GNSSmethod.

It is important to note that the GNSS-sounding does not precisely determine the $H_{\text {ion }}$, but the altitude can be presumed from physical principles. It is generally assumed that GNSSdetected perturbations are concentrated around the altitude of the maximum ionospheric ionization (hmF2), i.e., in the ionospheric F-layer. The $H_{\text {ion }}$ is usually taken between 250 and $400 \mathrm{~km}$, depending on solar, geomagnetic, seasonal and diurnal conditions. It should be noted that changing the $H_{\text {ion }}$ will change the IPP and SIP coordinates (Figure 2). This $H_{\text {ion }}$ ambiguity is the main disadvantage of the GNSS-sounding method that is otherwise widely and commonly used by the space science community to study the ionosphere. Below we demonstrate the use of GNSS-sounding for detection of earthquakes, tsunamis and volcano eruptions.

\section{Ionospheric response to earthquakes and tsunamis}

\subsection{Earthquakes \& tsunamis. Terminology.}

An earthquake is a shaking of the ground that results from the sudden release of energy in the lithosphere. The majority of earthquakes occur along faults - narrow zones where rocks move in relation to one another. The earthquake energy is released in the form of seismic waves. These waves can be of several types: "body waves" that propagate inside the volume (longitudinal P-waves and transverse S-waves), and "surface waves" that propagate along interfaces such as the surface of the Earth. Depending on the particle motion within the surface waves, they can be of Rayleigh (waves rolling along the ground) or of Love (horizontally polarized shear waves) type. As of today, the Rayleigh waves are the only type of seismic waves whose signatures were evidently detected in the ionosphere. The horizontal speed of the Rayleigh surface waves depends on their frequency and wavelength but typically varies between 3.3 and $4 \mathrm{~km} / \mathrm{s}$.

Earthquakes are characterized by several parameters. At an earthquake's onset, the rupture starts at the underground point called the hypocenter (or focus). The epicenter is a projection of the hypocenter's position onto the Earth's surface. Depending on the epicenter's position, earthquakes can be referred to as inland and submarine/undersea.

Earthquake's relative size is defined by a number called magnitude. Several magnitude scales have been developed in the past. However, the moment magnitude (Mw) scale that is 
directly related to the energy of an earthquake is the one commonly used by seismological authorities and by scientific communities.

Because earthquakes result from a slip along a fault, they are also characterized by the fault orientation (the focal mechanism), the fault dimensions, the amplitude and the orientation of the slip motion along the interface. With respect to their surface effects, earthquakes can be characterized by vertical and horizontal displacements.

There are three main types of focal mechanisms (Figure 3). Depending on the coseismic crustal motion at the surface this can be thrust (the upper block moves on top of the lower one), normal (the upper block moves downward) or strike-slip (the blocks move horizontally past one another). Hence, only thrust and normal type earthquakes, that are also referred to as dip-slip earthquakes, are characterized by significant vertical crustal motion.

The amplitude of the co-seismic vertical crustal displacements is the most important parameter for the generation of ionospheric perturbations. This displacement is related to the magnitude of an earthquake and, therefore, other characteristics, such as the fault dimensions and the type, contribute as well. These same parameters play a key role in the generation of tsunamis.

A tsunami (from Japanese "harbor wave") is an unusually large wave occurring in a result of the displacement of a large volume of water. Tsunamis are usually produced by submarine earthquakes, but can also be generated by landslides or underwater volcanic eruptions. The tsunami propagation speed depends on the depth of the ocean/sea and can be approximated by the following formula:

$$
v=\sqrt{g * d}
$$

where $g$ is the gravitational acceleration, and $d$ is the depth of the sea/ocean.

\subsection{Earthquakes and their signatures in the atmosphere and ionosphere}

During earthquakes, vertical displacements of the ground or of the ocean floor induce perturbations in the atmosphere and ionosphere (Figure 4). The ionospheric perturbations, called co-seismic ionospheric disturbances (CSID), are usually detected $\sim 8-9$ minutes after an earthquake. The Rayleigh surface waves generated by earthquakes, propagate along the Earth's surface and induce acoustic waves that $\sim 8-9$ min later can be registered in the ionosphere, similarly to CSID generated by the co-seismic crustal piston-like motion (Figure 4).

The theory describes that CSIDs, being of acoustic origin, are N-shaped (Figure 5a), i.e. 
an initial overpressure half-cycle with a relatively fast risetime and a slower pressure decay followed by a half-cycle of rarefaction [e.g., Zel'dovich and Raizer, 2002; Naugolnykh and Ostrovsky, 1998]. In reality, however, co-seismic ionospheric perturbations often have more complex waveforms (Figure 5b, c), occurring due to a superposition of signals from several sub-sources - co-seismic crustal uplift, the Rayleigh waves, tsunamis, etc.

\subsubsection{CSID and their main features. Ground-based observations}

The first observations of co-seismic atmospheric and ionospheric perturbations were made after the great Mw 9.2 earthquake that occurred on 28 March 1964 in Alaska, USA. Davies and Baker [1965] reported the first detection of ionospheric disturbances at Boulder Doppler sounder station $\sim 15 \mathrm{~min}$ after the Alaskan earthquake. The observed perturbations were suggested to be the manifestation of long-period ducted acoustic-gravity waves emitted into the ionosphere near the epicenter. Leonard and Barnes [1965] registered CSID generated by the 1964 Alaskan earthquake at several ionosonde stations located in the continental USA and Hawaii. Since those first observations, CSID are routinely detected by Doppler sounders (e.g., Artru et al., 2004; Liu et al., 2006a,b; Chum et al., 2012; 2016), and more rarely - by the ionosondes [e.g., Maruyama and Shinagawa, 2014; Maruyama et al., 2017].

The development of the GNSS and permanent networks of ground-based GNSS-receivers has provided a new technique allowing continuous observations with better spatial coverage. Calais and Minster (1995) were the first to use the ionospheric GPS-TEC data for detection of ionospheric co-seismic perturbations over California after the 1994 Mw6.7 Northridge earthquake. Since that pioneering work, the GPS/GNSS-sounding allowed better understanding of the CSID and their properties. For instance, it is now demonstrated that earthquakes with moment magnitudes Mw>6.8 are very much probable to cause perturbations in the ionosphere (Perevalova et al., 2014). generated directly by co-seismic vertical crustal displacements (e.g., Calais and Minster, 1995; 1998; Afraimovich et al., 2001; 2010a,b; Heki and Ping, 2005; Lognonné et al., 2006; Astafyeva and Heki, 2009; Cahiyadi and Heki, 2013; Jin et al., 2015; Zettergren and Snively, 2015; Komjathy et al., 2016; Li et al., 2019). The far-field CSIDs are usually associated with the propagation of the Rayleigh surface waves (Ducic et al., 2003; Liu et al., 2006b; Astafyeva et al., 2009; Rolland et al., 2011a; Kakinami et al., 2013), or of the air surface waves (Astafyeva and 
Afraimovich, 2006; Liu et al., 2006a). In addition, large earthquakes can be accompanied by the acoustic resonance signatures in the ionosphere (Choosakul et al., 2006; Liu et al., 2011; Rolland et al., 2011b; Saito et al., 2011). Ionospheric perturbations generated by these different sub-sources can be distinguished by their propagation speed. Thus, CSID associated with the acoustic waves generated by the crustal motion propagate at 600-1000 m/s; CSID generated by Rayleigh surface waves have speeds similar to those of the source waves on the ground, i.e. $3.3-4 \mathrm{~km} / \mathrm{s}$. These different CSID components can be well seen in travel-time diagrams (TTD, or hodocrones) that show the TEC amplitude with respect to the distance from the epicenter and time (Figure 6). From TTD, first, one can verify whether the epicenter is the source of the observed TEC perturbations. Second, the apparent horizontal speed can be easily estimated from the TTD. Third, the TTD also allows tracking the distance of CSID propagation. For instance, Figure 6a shows continuous observations of CSID as far as $1900 \mathrm{~km}$ from the epicenter. One can also notice that the initial CSID propagating at $\sim 1 \mathrm{~km} / \mathrm{s}$ splits in two perturbations at $\sim 600-700 \mathrm{~km}$ of the epicentral distance (Figure $6 \mathrm{a}$ ). The velocities of the "new" perturbations are $3 \mathrm{~km} / \mathrm{s}$ and $0.6 \mathrm{~km} / \mathrm{s}$. This phenomenon was first observed by Astafyeva et al. (2009) on the example of the M8.3 1994 Kuril earthquake and was called twomode propagation of CSID. The "splitting" of CSID into faster and slower modes was explained by the difference in their propagation speed. The occurrence of multiple modes was later confirmed for several other large earthquakes, including the great Tohoku-oki earthquake of 11 March 2011 (e.g., Liu et al., 2011; Rolland et al., 2011b; Galvan et al., 2012; Kakinami et al., 2013; Jin et al., 2015), the M7.8 April 2015 Nepal earthquake (Reddy and Seemala, 2015; Tulasi Ram et al., 2017) and the 2005 Northern California offshore earthquake (Jin, 2018). Figure $6 \mathrm{~b}$ shows multiple-mode CSID observed by satellite G15 after the Tohoku-oki earthquake observed by Galvan et al [2012].

Besides the above-mentioned CSID components, some other types of co-seismic ionospheric signatures can be distinguished. Thus, during large earthquakes, the initial nearfield TEC enhancement is often followed by a significant long-term depletion (e.g., Saito et al., 2011; Tsugawa et al., 2011; Kakinami et al., 2012). Kakinami et al. (2012) analyzed TEC response to three largest submarine earthquakes in Indonesia, Chile, and Japan, and found that a TEC depletion occurred in all those cases just above the tsunami source area. Consequently, Kakinami et al. (2012) attributed the observed depletion to "the downwelling of the sea surface" due to the tsunami generation, and called it the "tsunamigenic ionospheric hole" (Figure 5c-d). Astafyeva et al. (2013a), however, argued that such depletion represents the negative half-phase of the $\mathrm{N}$-wave, and showed that the "hole" can occur following any 
large earthquake independently on the epicenter being located inland or undersea. These 354 latter conclusions were later supported by observations of TEC response to the inland Nepal earthquake of 25 April 2015 (Kamogawa et al., 2015), and by modeling (Shinagawa et al., 2013; Zettergren et al., 2017). Astafyeva et al. (2013a) also noticed that the strength and the longevity of the ionospheric depletions scale with the magnitude of earthquakes (Figure 7c). This observation indicates a close relationship between earthquakes' parameters and coseismic signatures in the ionosphere. More details can be found in the next Section.

\subsubsection{CSID and earthquake parameters}

Recently, it has been found out that the coupling between the ionosphere and the solid earth is very tight. For instance, Astafyeva et al. (2013a) analyzed TEC response to 11 earthquakes of different magnitude and found that the amplitude of the near-field CSID grows roughly linearly with the magnitude of an earthquake (Figure 7a), and with the magnitude of the co-seismic uplift (Figure 7b). Cahiyadi and Heki (2015) later confirmed such dependence for the magnitude of an earthquake. However, they have found no correlation between the uplift and the amplitude of the ionospheric response. Therefore, this subject requires more profound analysis.

The focal mechanism, a characteristic that describes the deformation in the source region (Figure 3) is another earthquake parameter that may have a crucial impact on the CSID waveform. Astafyeva and Heki (2009) analyzed TEC response to three earthquakes of different focal mechanisms (thrust, normal and a combination of the two). They showed that the waveform of the signal in the ionosphere repeated the initial crustal motion on the ground: the thrust earthquake caused normal $\mathrm{N}$-wave response in the ionospheric TEC, normal fault earthquake cause inversed $\mathrm{N}$-wave, while the TEC response to the mixed type earthquake showed both direct and inversed N-waves. However, Rolland et al. (2013) argued that such dependence might be an artifact caused by the magnetic field as shown in the next Section.

With respect to the focal mechanism, it is of interest to study the ionospheric response to strike-slip fault earthquakes (i.e., earthquakes with small vertical crustal motion) and that do not generate large tsunamis. Astafyeva et al. (2014) analyzed TEC response to six large strike-slip earthquakes that occurred in 2001-2013 and found that the response in the ionospheric TEC was almost as strong as for perturbations caused by dip-slip earthquakes. They also showed that the scaling law for the CSID amplitude increasing with the magnitude 
is also true for strike-slip earthquakes. Contrary to those results, Cahiyadi and Heki (2015) demonstrated that strike-slip earthquakes generate CSID with weaker amplitudes than dipslip earthquakes of similar magnitudes.

The observation of ionospheric response to strike-slip earthquakes remains one of the open questions and is still difficult to explain. Astafyeva et al. (2014) suggested that in absence of significant vertical static co-seismic displacements of the ground, other seismological parameters (primarily the magnitude of co-seismic horizontal displacements, seismic fault dimensions, seismic slip or dip angle) may contribute in the generation of largeamplitude ionospheric perturbations. Future studies, especially modeling of the ionospheric response to strike-slip fault earthquakes, will shed light on this mystery.

\subsubsection{CSID and the propagation medium parameters}

It is known that the amplitude and the waveform of CSID are largely controlled by observational factors, such as the geometry of GNSS-sounding, geomagnetic field and the background ionization [e.g., Calais and Minster, 1995; Heki and Ping, 1995; Afraimovich et al., 2001; Rolland et al., 2013; Cahyadi and Heki, 2015].

The amplitude of ionospheric perturbations detected by the GNSS-method, experiences strong azimuthal dependence due to the integral character of transionospheric sounding. When a perturbation's wave vector and satellite-to-receiver LOS are perpendicular to each other, we observe perturbation of the largest amplitude. Otherwise, if the wave vector is parallel to LOS, the integration of wavefronts cancels the wave phases and, therefore, results in the minimum amplitude of perturbation (e.g., Afraimovich et al., 1998; 2001; Bagiya et al., 2017a).

Further, as explained above, the magnetic field configuration at the epicentral area has a major impact on the amplitude and waveform of CSID propagating in the ionospheric F region. Rolland et al. (2013) computed the ionospheric radiation pattern, and showed that the magnetic field impact is somewhat different for the positive and negative sub-phases of CSID (Figure 8). The positive part is attenuated for CSID propagating at angles exceeding $\pm 10^{\circ}$ to the magnetic field lines, and significantly attenuated for angles larger than $\pm 30^{\circ}$. On the north from the epicenter in the Northern Hemisphere (i.e. poleward from the epicenter), only the weakened negative part of the signal can be seen. These modeling results are in line with observations showing that CSID do not propagate far in the poleward or quasi-poleward direction and fade out very fast (e.g., Otsuka et al., 2006; Astafyeva and Heki, 2009; Rolland et 
421 al., 2013). Whereas, the equatorward propagation is favored, and CSID can be observed 422 farther from the source and they have larger amplitudes (Figure 8).

The background ionospheric parameters (i.e., the electron density, absolute vertical TEC) also play a significant role in CSID amplitude. Hence, in order to compare amplitudes of CSID generated by different earthquakes, normalization on the background ionospheric parameters should be done [Cahiyadi and Heki, 2015].

\subsubsection{Space-borne observations of CSID}

The development of new space missions made it possible to detect atmospheric and ionospheric perturbations directly in space. Thus, Garcia et al. (2013) analyzed data of neutral mass density calculated from accelerometers onboard Gravity Field and Steady-State Ocean Circulation Explorer (GOCE) spacecraft with orbital altitude $\sim 250 \mathrm{~km}$, and presented the first in situ observations of a post-seismic infrasound wavefront. The atmospheric infrasound signals due to the great Tohoku-oki earthquake of 11 March 2011 induced variations of air density and vertical acceleration of the GOCE platform. Perturbations up to $11 \%$ in the air density and $1.35^{*} 10^{-7} \mathrm{~m} / \mathrm{s} 2$ in vertical acceleration were reported. Yang et al. (2014) observed co-seismic ionospheric TEC and atmospheric density perturbations at the altitude of $\sim 450 \mathrm{~km}$ by using data of Gravity Recovery and Space Experiment (GRACE) satellite. The perturbations were generated by the Tohoku-oki earthquake in Japan but were detected over Alaska, 8 minutes after the arrival of seismic and infrasound waves on the ground. Yang et al. (2014) also reported sudden changes in GRACE acceleration following the Tohoku-oki earthquake.

Furthermore, space-borne observations shed light on the vertical scale of CSID, a feature that remains unknown. Sun et al. (2016) used data from satellite mission FORMOSAT3/COSMIC and GPS radio-occultation technique, and, on the example of the Mw7.8 April 2015 Nepal earthquake, demonstrated that the earthquake-induced perturbations penetrate into the ionosphere at supersonic speeds of approximately $800 \mathrm{~m} / \mathrm{s}$. The corresponding change in the electron density structure reach $10 \%$ near the maximum ionization height (hmF2). The vertical scale of the perturbation was found to be of $150 \mathrm{~km}$, and the hmF2 was uplifted by more than $30 \mathrm{~km}$ within $1 \mathrm{~min}$. These results showed that earthquakes represent a significant force that perturbs the vertical structure of the ionosphere.

\subsection{Tsunamis and their signatures in the atmosphere and ionosphere}


Tsunamis propagating along the ocean surface generate internal gravity waves that, unlike the acoustic waves, propagate obliquely. Because of the low vertical velocity of $\sim 50$ $\mathrm{m} / \mathrm{s}$, the tsunami-generated gravity waves reach the ionospheric heights in $\sim 45-60$ min after their generation on the surface (Figure 4). The co-tsunamic ionospheric disturbances (CTID) are usually characterized as quasi-periodic structures with typical periods between 10 and 30 min (Figure 9a,b). CTID can be detected in the vicinity of earthquakes' epicenters soon after they are generated, so that CTID can be seen in TTD together with co-seismic ionospheric perturbations observed in the near-epicentral area (Figure 6b). Also, CTID can be observed in open sea/ocean (by using GNSS data on islands), and/or upon their arrival on shores. CTID match the period, velocity, and propagation direction of the tsunamis causing them. Consequently, tracking CTID provides an opportunity to follow the propagation of tsunamis and can potentially be used for near-real-time tsunami warning systems (e.g., Najita et al, 1974; Savastano et al., 2017).

\subsubsection{CTID and their main features. Ground-based observations}

Hines [1972] and Peltier\&Hines [1976] were the first who theoretically predicted that sea surface variations typical of tsunamis can seed internal gravity waves with amplitudes strong enough to generate ionospheric signatures. The first GPS-detection of tsunami-driven ionospheric perturbations belongs to Artru et al. (2005). The Mw=8.2 earthquake in Peru on 23 June 2001 generated a tsunami in the Pacific Ocean that reached the coast of Japan 22 hours later. Artru et al. (2005) used data from the Japanese Network of GPS-receivers GEONET and observed small-scale TEC perturbations over Japan and up to $400 \mathrm{~km}$ offshore.

The giant tsunami of December 2004 in the Indian Ocean with maximum wave heights of $10 \mathrm{~m}$ generated significant perturbations in the ionosphere that were observed by different techniques and methods. Liu et al. (2006a) reported the detection of CTID registered by GPSreceivers in the Indian Ocean area. The observed CTID with periods of 10-20 min, and horizontal wavelengths of 120-240 km traveled away from the epicenter with an averaged horizontal speed in the ionosphere of about 190 m/s. Das Gupta et al. (2006) also used data from ground-based GPS-receivers and reported observations of CTID of a quite significant amplitude of 1.5 to 2 TECU. The perturbations occurred within 45 minutes of the quake at stations situated near the east coast of the Indian subcontinent. These ionospheric observations showed good agreement between the CTID parameters and those of the tsunami, providing strong evidence of the tsunami-ionosphere coupling. Subsequent studies by Rolland et al. (2010) and Galvan et al. (2011) brought more observational evidences of the ionosphere 
sensitivity to tsunami-generated gravity waves. By using data of GPS-receivers located in Hawaii and in Japan, they showed tsunami-associated TEC fluctuations of the order of 1\% of the background TEC value. Comparison with oceanic data from Deep-ocean Assessment and Reporting of Tsunamis (DART) buoys showed similarity in the waveform and in the spectral signatures of the ionospheric and oceanic data.

The great March 2011 Tohoku tsunami, with wave heights reaching up to $38 \mathrm{~m}$ in Ofunato region of Japan, opened a new era in the ionospheric detection of tsunamis. The GEONET, the World's most advanced network of GPS-receivers, allowed the first-time detection of CTID in the near-field of the seismic source (e.g., Liu et al., 2011; Rolland et al., 2011b; Tsugawa et al., 2011; Galvan et al., 2012; Komjathy et al., 2012; Occhipinti et al., 2013; Jin et al., 2014). The Tohoku tsunami was also detected in the far-field, i.e., several thousand kilometers from the epicenter, by using different techniques. Data from ground-based GPS receivers enabled ionospheric detection of the Tohoku tsunami near the Hawaiian Islands (e.g., Makela et al., 2011; Occhipinti et al., 2011), and near the west coast of North America (Crowley et al., 2016; Azeem et al., 2017). In addition to the GPS-TEC data, the Tohoku tsunami was observed in the airglow layers at altitudes near $250 \mathrm{~km}$, which was the first detection of tsunami-related perturbations in the airglow (Makela et al., 2011; Figure 9c). Images were taken by ground-based wide-angle camera system located at the top of the Haleakala Volcano on Maui, Hawaii, and showed good correlation with GPS measurements of the TEC from Hawaii GPS stations and the Jason-1 satellite. After that first-time registration, the tsunami-induced airglow signatures were also observed following the 2012 Haida Gwaii, the 2015 Illapel and the 2010 Chile earthquakes (Grawe and Makela, 2015; 2016). These works demonstrated the utility of monitoring of the Earth's airglow layers for tsunami detection and tracking.

Observations of the airglow response to the 2011 Tohoku tsunami revealed another interesting phenomenon: the occurrence of signatures in magnetically conjugate regions. Simulation results presented in Huba et al. [2015] indicated that gravity wave-induced variations in the electric field can map to the conjugate hemisphere where they impact the ionospheric TEC and $630 \mathrm{~nm}$ airglow emission. This result, however, needs to be confirmed with further observational studies.

Finally, it is interesting to note that CTID can, in some cases, arrive before tsunamis (Makela et al., 2011; Bagiya et al., 2017b). Bagiya et al (2017b) explained the generation of such ahead of tsunami ionospheric disturbances by dissipation of transverse mode of the 
primary acoustic-gravity waves generated by tsunamis. This can be useful to short-term 523 tsunami forecasts.

\subsubsection{Space-borne observations of CTID}

Besides ground-based instruments, tsunami-driven atmospheric and ionospheric signatures were detected by space-based equipment. Garcia et al. (2014) used data from GOCE satellite and observed the Tohoku tsunami-driven perturbations in the air density. Coisson et al. (2016) presented the first observations of the tsunami-gravity waves by using ionospheric radio-occultation data from COSMIC constellation. Yang et al. (2017) used data from the Sounding of the Atmosphere using Broad-band Emission Radiometry (SABER) spacecraft and observed significant perturbations of nightglow emissions in the mesosphere. The perturbations were caused by tsunami waves of the 2015 Chile and 2011 Tohoku earthquake/tsunami events.

atmospheric and ionospheric response to earthquakes and tsunamis. These results can already be used to track tsunamis propagating in the far-field and to predict their arrivals to distant coasts. The next frontier question is - can it be possible to use our knowledge on CSID and CTID to trace tsunamis generated in the near-field from the source? For a short-time tsunami warning, one needs to know in near-real time the information about the seismic source (i.e., the magnitude of the co-seismic vertical crustal displacements and/or the fault dimensions). While this task still remains challenging for the "classic" seismology [LaBreque et al., 2017], it may be addressed in future to the Ionospheric Seismology - a new branch of

\subsection{Ionospheric Detection of Earthquakes and Tsunamis. "Ionospheric Seismology"}

In earlier times, the term "Ionospheric Seismology" was used to describe a branch of Geophysics studying the ionospheric response to earthquakes and to tsunami propagation. Nowadays, the Ionospheric Seismology is becoming more of the use of ionospheric measurements for seismological purposes: to localize the seismic source, to estimate the dimensions of the seismic fault, or -in future- to estimate the magnitude of an earthquake or the height of tsunami waves from ionospheric data and observations. All these tasks are yet quite challenging but have a very important perspective for the future - the possibility to use 
ionospheric measurements for near real-time tsunami warning systems (e.g., Najita et al., 1974; Kamogawa et al., 2016; Savastano et al., 2017; Occhipinti, 2015).

With regard to the new definition of the Ionospheric Seismology, the first detection of the seismic source from the ionosphere was done by Afraimovich et al. (2006). By using data from ground-based GPS-receivers, they first analyzed CSID generated by the 2003 Tokachi-oki earthquake in Japan. Then, assuming that the CSID propagate from a point source at a constant speed as a spherical wave, Afraimovich et al. (2006) managed to determine the position of the CSID source in the vicinity of the epicenter. This method was later successfully tested for detection of the seismic source of several other large earthquakes that occurred in Japan and in Sumatra in 1994 - 2006 (Afraimovich et al., 2006; Kiryushkin and Afraimovich, 2007; Astafyeva et al., 2009; Kiryushkin et al., 2011).

Liu et al. (2010) developed an ionospheric method based on the raytracing and the beam-forming techniques, and successfully localized the epicenter of the 1999 Chi-Chi earthquake in Taiwan from ionospheric measurements. Tsai et al. (2011) traced the epicenter of the Tohoku-oki earthquake and the origin of the tsunami from ionospheric TEC observations of co-seismic and co-tsunamic ionospheric perturbations. Their results for both the tracked epicenter and the tsunami origin were close to those reported by the USGS. More recently, Lee et al. (2018) localized the seismic source of the 2016 Kaikoura earthquake in New Zealand by applying for the first time an ionosphere-based backprojection method. The Mw7.8 Kaikoura earthquake resulted from a complex multi-fault rupture (e.g., Bagiya et al., 2018), and Lee et al. (2018) estimated the source region located around the maximum uplift area.

Therefore, nowadays it is certainly possible to determine the position of the seismic source from the ionosphere. Going further forward, a more challenging task is to understand the seismic source structure from the ionosphere. Several works have shown that this can be achieved. Heki et al. (2006) used ionospheric TEC measurements and managed to reproduce the rupture process of the M9.1 2004 Sumatra earthquake. Heki et al. (2006) also demonstrated that the complex waveform of the observed co-seismic TEC variations was due to the contribution of several sub-faults ruptured during the earthquake.

Astafyeva et al. (2011) introduced for the first time a method of ionospheric imagery of seismic fault, the "seismo-ionospheric imagery". They used high-rate 1Hz GPS-TEC data and, on the example of the 2011 Tohoku-oki earthquake, obtained the ionospheric "imprint" of the co-seismic uplift. It should be reminded that the seismic source generating CSID, is also responsible for the generation of tsunamis; consequently, this method, once adapted for 
systematic imagery, can be used for future ionosphere-based tsunami warning systems. One

591 of the biggest advantages of the seismo-ionospheric imagery is the timing, since the first CSID occur in the ionosphere $\sim 8 \mathrm{~min}$ after an earthquake. This means that by using the ionospheric TEC data in quasi-real time, it is possible to obtain information about the location and dimensions of the source of a tsunami within several minutes after a quake. For instance, in the case of the Tohoku-oki earthquake, the first arrival of the tsunami was recorded between 26 and 35 minutes after the earthquake had struck, so that the 17 minutes of remaining time could be used for ionosphere-based tsunami warning systems in near-real time.

To examine the possibility of the use of the ionosphere-based imagery systematically, Astafyeva et al. (2013b) analyzed the geometry of GPS-sounding for multiple satellites during the Tohoku-oki earthquake. They found that the seismo-ionospheric imagery is only possible upon detection of the primary acoustic waves coming directly from the epicentral area. Astafyeva et al. (2013b) also demonstrated that plotting standard snapshots of TEC over the epicentral area is useful to retrieve the information about the seismic source structure. Thus, for the case of the 2011 Tohoku-oki earthquake, two areas of enhanced TEC simultaneously occurred at $\sim 150 \mathrm{~km}$ eastward from the epicenter starting from $510 \mathrm{sec}$ after the earthquake (Figure 10b). The location of these two TEC enhancements corresponded to the location of two segments of co-seismic crustal slip as it was shown by seismologists (e.g., Simons et al., 2011; Bletery et al., 2014; Figure 10a). More recently, Thomas et al. (2018) and Astafyeva \& Shults (2019) demonstrated that the GNSS seismo-ionospheric imagery can work for moderate earthquakes as well. Astafyeva and Shults (2019) also noted that lower resolution data sampling, such as 15 -sec or 30 -sec, which so far is a standard resolution for GNSS data, will, most likely, not work efficiently.

Kamogawa et al. (2016) suggested a method based on observations of "tsunamiionospheric hole" as potentially useful for near real-time tsunami warnings. Kamogawa et al. (2016) found a quantitative relationship between the initial tsunami height and the TEC depression rate caused by the hole from seven tsunamigenic earthquakes in Japan and Chile. They showed that the percentage of TEC depression and initial tsunami height are correlated. Another promising study was recently done by Rakoto et al. (2018), who performed for the first time an inversion of the tsunami wave height from ionospheric TEC measurements. Occhipinti et al. (2018) introduced for the first time so-called "ionospheric surface wave magnitude", a new way to characterize earthquakes by observing the signature of surface Rayleigh waves in the ionosphere. 
It is important to note that all those methods were proposed based on examples of past earthquakes, and so far they can only potentially be used for ionospheric near-real-time detection of earthquakes and for tsunami warnings. Going towards the real-time application, Savastano et al. (2017) made the first preliminary feasibility demonstration for near real-time ionosphere monitoring by GNSS-sounding. Their approach has been implemented at several GNSS-receivers around the Pacific Ocean (https://iono2la.gdgps.net), and is aiming -in the future- to detect CTIDs in near-real time.

\section{Ionospheric response to volcanic eruptions}

\section{3}

\subsection{Volcanic eruptions. Terminology}

A volcanic eruption is a sudden ejection of matter from the earth's interior through a volcanic vent. Eruptions can be effusive, with outflows of hot lava, or explosive, throwing out huge amounts of rock with volcanic ash and gases. The style and evolution of volcanic eruptions are dictated by the fluid mechanics governing magma ascent (Gonnermann and Manga, 2007).

The intensity of eruptions is usually estimated by the Volcanic Explosivity Index (VEI) on the scale from 0 to 8 . The VEI is a characteristic similar to a magnitude for earthquakes. VEI=0 eruptions are continuous eruptions, while the recurrence of VEI=8 eruptions is 1 per 50,000 years. Up to date, there are only records of ionospheric response to explosive eruptions with VEI from 2 to 6.

Volcanic eruptions are usually preceded by a series of small earthquakes, known as seismic tremor. The tremor can last from several tens of minutes to several days.

\subsection{Volcanic eruptions and their signatures in the atmosphere and ionosphere.} Ground-based and space-borne observations

Explosive volcanic eruptions can generate a broad spectrum of pressure oscillations, from infrasonic to gravity waves (e.g., Kanamori, Mori, 1992; Kanamori et al., 1994). At the near-ground level, eruptions generate infrasound waves (acoustic domain, below $20 \mathrm{~Hz}$ ) that can propagate for very long distances (e.g., Matoza et al., 2011; Fee and Matoza, 2013; Ripepe et al., 2010). Whereas, lower frequency oscillations (between 0.97 and $3.5 \mathrm{mHz}$ ), typical of atmospheric gravity waves are quite rare to observe and can only be captured in the vicinity of eruptions (De Angelis et al., 2011). 
Besides the near-surface perturbations, and similar to earthquakes and tsunamis, volcanic eruptions can generate atmospheric and ionospheric perturbations (Figure 11). In the atmosphere, the shock of the volcanic eruption can trigger mesospheric gravity waves (or mesospheric airglow waves) as shown in Figure 12a for the 23 April 2015 eruption of Calbuco

661 662 663 664 665 666 667 668 669 670 volcano in Southern Chile. Such "night glow" can be emitted from a variety of gases located near the mesopause $(80-105 \mathrm{~km})$.

In the ionosphere, volcanic eruptions generate so-called co-volcanic ionospheric disturbances (CVID). The CVID are usually quasi-periodically shaped and occur $\sim 10$ to 45 minutes after the eruption onset (Figure 13). Up to now, only a few reports on detection of CVID have been done, and our knowledge on CVID, their generation and evolution is not yet sufficient.

Heki (2006) was the first who detected CVID in the ionospheric TEC. By using data from the GEONET, Heki (2006) studied the ionospheric response to the 1 September 2004 Asama volcano explosion in Japan. The moderate VEI=2 explosion caused a small-amplitude $\sim 0.03$ 0.16 TECU ionospheric response $\sim 12$ minutes after the beginning of the explosion. The apparent velocity of the observed TEC perturbations was estimated to be $\sim 1.1 \mathrm{~km} / \mathrm{s}$, which is close to the speed of the acoustic and shock-acoustic waves in the ionosphere. The dense coverage of the Japanese network of GPS-receivers GEONET allowed detecting the response as far as $200 \mathrm{~km}$ away from the volcano. From the ionospheric GPS-TEC measurements Heki (2006) estimated the energy of the Asama volcano explosion as of $2 \times 10^{14} \mathrm{~J}$.

Dautermann et al. (2009a) used data of GPS-receivers located around Guadeloupe, Antigua and the Caribbean to analyze the ionospheric TEC response to the 13 July 2003 VEI=3 explosion of the Soufrière Hill Volcano in Montserrat, Lesser Antilles. They observed quasiperiodic TEC oscillations with a period of about $12 \mathrm{~min}$; the TEC response appeared $\sim 18 \mathrm{~min}$ after the explosion and lasted for about $40 \mathrm{~min}$ (Figure 13a). Overall, the co-volcanic TEC perturbations were registered as far as $\sim 700-800 \mathrm{~km}$, and their propagation speed was estimated to be $\sim 550-650 \mathrm{~m} / \mathrm{s}$. Spectral analysis revealed peaks centered at 1 and $4 \mathrm{mHz}$, which is consistent with the theory, suggesting both gravity and acoustic wave components. Dautermann et al. (2009b) used a normal mode summation technique and showed that the 4 $\mathrm{mHz}$ peak can be explained by a single explosive source in the atmosphere. However, they struggled to explain the quasi-periodic signal that occurred later. Similarly to Heki (2006), Dautermann et al. (2009a) used TEC-observations to calculate the energy of the volcano explosion: for the Soufrière Hill case it was estimated to be $1.53 \times 10^{10} \mathrm{~J}$. 
Nakashima et al. (2016) analyzed the TEC response to the Kelud volcano explosion of 13 691 February 2014 in Java, Indonesia. The eruption lasted from 16:01UT to 18:00UT. By using ground-based GNSS-receivers from several regional networks in Sumatra and Indonesia, they observed TEC oscillations that commenced at 16:25 UT and lasted until 19:00UT. The amplitude spectrum of the TEC data series showed peaks at $3.7 \mathrm{mHz}$ and $4.8 \mathrm{mHz}$, suggesting that the observed TEC oscillations were due to the coupling between the solid Earth and the lower atmosphere known as the acoustic resonance.

The April 2015 eruptions of the Calbuco Volcano in southern Chile received more 698 attention from the scientific community. On 22 April 2015 the Calbuco volcano awoke after 43 years of inactivity. The first eruption began at 21:04 UT, lasted 90 minutes and generated a gray ash plume that arose $15 \mathrm{~km}$ above the crater. A larger second event began at 04:00UT on 23 April, it lasted six hours, and generated an ash plume that rose higher than $15 \mathrm{~km}$. Possibly because of strong winds, the ash plume from this second eruption drifted northward, northeastward, and eastward (Figure 12b). The VEI was estimated 4 for these two events (http://www.sernageomin.cl; http://www.onemi.cl).

The ionospheric TEC response to the Calbuco eruptions was analyzed by several research groups. Shults et al. (2016) used data of ground-based GNSS receivers and observed quasi-periodic ionospheric TEC oscillations following the two eruptions. The TEC response was registered $\sim 15$ minutes after the beginning of the first eruption (Figure 13b) and $\sim 40$ minutes after the second eruption (Figure 13c). Shults et al. (2016) explained such a time delay in ionospheric responses by different source waves emitted by the eruptions. Most likely, the first eruption, being the first in 43 years, was initiated by a shock acoustic wave, and continued by the gravity waves generated by the ash emission. During the second eruption, only ash plume was emitted, and produced such a late response in the ionosphere. Shults et al. (2016) estimated the apparent velocities of the CVID to be in the range of 900$1200 \mathrm{~m} / \mathrm{s}$.

Atmospheric-ionospheric disturbances generated by the April 2015 Calbuco eruptions were also studied by X. Liu et al. (2017). By using data from 50 GPS stations, they observed TEC disturbances with an amplitude of 0.1-0.4 TECU about one hour after the eruptions. The disturbance lasted more than one hour for the first eruption and about half an hour for the second eruption. The propagation velocities were around $800 \mathrm{~m} / \mathrm{s}$ and $900 \mathrm{~m} / \mathrm{s}$ for the two eruptions, respectively. The spectrogram of the filtered TEC time series was centered at 3.7 $\mathrm{mHz}$, which is in the frequency range of infrasonic waves. 
It is interesting to note that, similar to earthquakes, the amplitude of CVID seems to scale with the intensity of volcanic eruptions. Thus, a VEI=2 explosive eruption can generate small TEC perturbations of about 0.1 TECU, while a VEI=4 eruption causes a stronger response in the ionosphere when the TEC perturbations can reach 0.45 TECU. The relative contribution of the CVID into the background TEC for VEI $=2$ eruptions is $\sim 8 \%$, and reaches $15-18 \%$ for VEI=4 eruptions (Shults et al., 2016).

\subsection{Ionospheric detection of volcanic eruptions. "Ionospheric Volcanology"}

Similarly to the Ionospheric Seismology discussed in P2.3, the term "Ionospheric Volcanology" has been introduced by Shults et al. (2016) to define the use of ionospheric measurements for the interests of volcanology. For instance, to detect an eruptive volcano and/or to determine the time of an eruption's onset from the ionosphere.

Shults et al. (2016) were the first and so far the only to localize an eruption from the ionosphere. To do so, they used a method similar to that proposed by Afraimovich et al. (2005) for the ionospheric detection of earthquakes. This method is based on the approximation of a spherical wave propagating from a point source at a constant speed.

This ionosphere-based method allows not only to localize the source but also to estimate the source onset time. Normally, the time of the eruption onset can be calculated from nearlylocated seismometers or/and from infrasound stations (e.g., Matoza et al., 2011; Caudron et al., 2015). However, the absence of seismometers within $100 \mathrm{~km}$ from a volcano would not allow to estimate the eruption time with high precision. Therefore, an ionosphere-based method can be used in the areas with no seismometers installed.

The results from Shults et al. (2016) on the ionospheric localization for both Calbuco eruptions are presented in Figure 14(a-b). One can see that for the first eruption, the source of the ionospheric perturbation can be localized sufficiently well. The position of the eruption was estimated within \pm 1 -2 degrees of latitude and/or longitude. From their method, Shults et al. (2016) calculated the time of the first eruption's onset between 21.07UT and 21.29UT; these ionosphere-based results were close to the onset time calculated from seismometers (21.07UT) and to that from infrasound stations (21.16UT $\pm 0.12 \mathrm{~h}$; Matoza et al., 2018).

For the second eruption, the ionosphere-based localization method showed the eruption located on the northeast from the volcano (Figure 14b). Shults et al. (2016) suggested that such a discrepancy occurred, most likely, because of the significant impact of horizontal atmospheric winds on vertical propagation of CVID. Otherwise, it can be due to the 
volcanic plume (and, therefore, the atmospheric source) drift toward north-east as satellite images show (Figure 12b). The ionospherically-estimated source time varied from 4.78 to 4.98UT, which is about 45-55 minutes behind the onset time estimated from the seismometers and from the infrasound stations. Shults et al. (2016) explained this delay by "the late occurrence and registration of the CVID after the second eruption", which was 60 min (Figure 13), as compared to $15 \mathrm{~min}$ in the first eruption.

Therefore, ionospheric measurements can help to detect an eruptive volcano and to estimate the eruption onset. Also, they provide indirect information on the position and drift of the volcanic ash plume. However, more work is needed to improve the existing methods and to obtain more precise results.

\section{Future perspectives}

Over the past two decades, we have substantially enlarged our knowledge about ionospheric signatures of $\mathrm{NH}$. Together with recent advances in the ionospheric remote sensing, this opens new exciting perspectives for future applications of ionosphere-based methods for detection of NH. For instance, the seismo-ionospheric imagery by using GNSS data with high temporal and spatial resolution could provide information on the seismic source extent. Furthermore, in the near future, we expect to be able to make an inversion of seismic source parameters from ionospheric observational data. The latter will provide information on the co-seismic crustal uplift, and will bring improvements for tsunami warnings systems. In addition, future satellite missions with on-board airglow cameras will help to track tsunami propagation over the entire oceans before they hit the coasts.

However, it should be noted that the development of such ionosphere-based methods still requires better understanding of the Solid Earth/ocean/atmosphere/ionosphere coupling. Along with new observational facilities, the development of new simulation tools is necessary to further advance in this branch of Geophysics. Models help understand the coupling, interpret the observations and forecast the ionospheric response. Within the past two decades, numerous simulation techniques have been developed. For instance, ray-tracing is the simplest, although not the most precise, way to reproduce near-field ionospheric signatures of earthquakes and volcanic eruptions [Calais et al., 1998; Heki and Ping, 2005; Heki et al., 2006; Rolland et al., 2013; Dautermann et al., 2009a; Thomas et al., 2018]. To model CSID propagation in the far field and the ionospheric signatures of Rayleigh surface waves and tsunamis, normal mode summation technique shows promising results [Lognonné 
et al., 1998; Artru et al., 2001; 2004; Rolland et al., 2011a; Coisson et al., 2015; Rakoto et al., 2018]. Further, to reproduce co-seismic and co-tsunamic signatures with better accuracy, especially those generated by giant earthquakes, more sophisticated physics-based models have been recently developed [e.g., Occhipinti et al. 2006, 2008; Krasnov et al., 2007; Kherani et al., 2009; 2012; Shinagawa et al., 2013; Huba et al., 2015; Chum et al., 2016; Brissaud et al., 2016; 2017; Meng et al., 2015; 2018; Zettergren and Snively, 2015; Zettergen et al., 2017]. For instance, taking into account non-linear processes upon wave propagation in the atmosphere allowed to reproduce the co-seismic ionospheric hole [Zettergen et al., 2017; Shinagawa et al., 2013].

It should be pointed out that the development of accurate modeling tools is also crucial for the future application of seismo-ionospheric methods for other planets than Earth, which is another exciting perspective for this branch of geophysics. Seismometers are the traditional instruments used for studying the seismic and volcanic activities of a planet. Whereas, the newly introduced atmospheric/ionospheric seismology/volcanology via remote atmospheric/ionospheric monitoring is a novel way to explore the planetary seismicity and to learn about the formation and evolution of a planet. Addressing these fundamental questions remains so far only a dream for humanity. In November 2018, Mars has finally got the first seismometer with the planetary mission InSight (https://mars.nasa.gov/insight/), so that we can expect new scientific discoveries concerning the Red Planet's interior quite soon. However, our knowledge about another telluric planet -Venus- is still quite poor. The situation is complicated by the adverse surface conditions on Venus, with extremely high atmospheric temperature and pressure. The latter makes it impossible to place a seismometer on the surface for an extended period of time. Therefore, for Venus, the remote monitoring of atmospheric perturbations can be the only way to detect signs of seismic/volcanic activity and to unveil the biggest mysteries of the Universe.

\section{Acknowledgements}

This work was initiated under the support of the European Research Council (ERC, grant agreement 307998). The author is grateful to Anthony Sladen (GéoAzur) and Chloé Michaut (ENS de Lyon) for their kind help with some parts of the Manuscript. GPS data shown in Figures 5b, 6a are from the Japanese GNSS Earth Observation Network System (GEONET) and can be accessed from the Geospatial Information Authority of Japan (GSI) database via the following service: http://datahouse1.gsi.go.jp/terras/terras_english.html. Data shown in 
Figure 13b-c are available from the SOPAC (http://sopac.ucsd.edu), UNAVCO (http://unavco.org), and RAMSAC (http://www.ign.gob.ar) online data services. No other data were used in this review. This is IPGP contribution 4086.

\section{References:}

Afraimovich, E.L., K.S. Palamartchouk, N.P. Perevalova (1998) GPS radio interferometry of travelling ionospheric disturbances. J. Atmos. Sol.-Terr. Phys., 60 (12), 1205-1223.

Afraimovich, E.L., N.P. Perevalova, A.V. Plotnikov and A.M. Uralov (2001), The shock-acoustic waves generated by the earthquakes, Ann. Geophys., 19(4), 395-409.

Afraimovich, E.L., E.I. Astafieva, V.V. Kirushkin (2006) Localization of the source of ionospheric disturbance generated during an earthquake. International Journal of Geomagnetism and Aeronomy, V.6, GI2002, doi:10.1029/200403000092.

Afraimovich, E., D. Feng, V. Kiryushkin, E. Astafyeva (2010a). Near-field TEC response to the main shock of the 2008 Wenchuan earthquake. Earth, Planets, Space, V.62, No.11, 899-904, doi:10.5047/eps.2009.07.002.

Afraimovich, E.L., Ding Feng, V.V. Kiryushkin, E.I. Astafyeva, Shuanggen Jin, and V.A. Sankov (2010b). TEC response to the 2008 Wenchuan earthquake in comparison with other strong earthquakes. International Journal of Remote Sensing, 31(13), doi:10.1080/01431161003727747.

Afraimovich, E.L. et al. (2013) A review of GPS/GLONASS studies of the ionospheric response to natural and anthropogenic processes and phenomena, J. Space Weather Space Clim., 3, A27, doi:10.1051/swsc2013049.

Artru, J., P. Lognonné, and E. Blanc (2001), Normal modes modelling of post-seismic ionospheric oscillations, Geophys. Res. Lett., 28(4), 697-700, doi:10.1029/2000GL000085.

Artru, J., Farges, T., Lognonne, P. (2004). Acoustic waves generated from seismic surface waves: propagation properties determined from Doppler sounding observation and normal-modes modeling. Geophys. J. Int. 158, 1067-1077.

Artru, J., V. Ducic, H. Kanamori, P. Lognonné, and M. Murakami (2005), Ionospheric detection of gravity waves induced by tsunamis, Geophys. J. Int., 160, 840-848, doi:10.1111/j.1365246X.2005.02552.x.

Astafyeva E.I. and Afraimovich E.L. (2006), Long-distance propagation of traveling ionospheric disturbances caused by the great Sumatra-Andaman earthquake on 26 December 2004, Earth, Planets and Space, V.58, N8, 1025-1031. 
Astafyeva, E. and K. Heki. (2009) Dependence of waveform of near-field coseismic ionospheric disturbances on focal mechanisms. Earth, Planets, Space, V. 61, No.7, 939-943.

Astafyeva, E., K. Heki, E. Afraimovich, V. Kiryushkin, S. Shalimov (2009). Two-mode longdistance propagation of coseismic ionosphere disturbances. J. Geophys. Research, V. 114, A10307, doi:10.1029/2008JA013853.

Astafyeva, E., P. Lognonné, L. Rolland (2011), First ionosphere images for the seismic slip on the example of the Tohoku-oki earthquake. Geophys. Res. Lett., V.38, L22104, DOI:10.1029/2011GL049623.

Astafyeva, E., Shalimov, S., Olshanskaya, E., Lognonné, P. (2013a) Ionospheric response to earthquakes of different magnitudes: larger quakes perturb the ionosphere stronger and longer. Geophys. Res. Lett., V.40, N9, 1675-1681, DOI: 10.1002/grl.50398.

Astafyeva, E., L. Rolland, P. Lognonné, K. Khelfi, T. Yahagi. (2013b) Parameters of seismic source as deduced from $1 \mathrm{~Hz}$ ionospheric GPS data: case-study of the 2011 Tohoku-oki event. J. Geophys. Res., V. 118, 9, 5942-5950. DOI:10.1002/jgra50556.

Astafyeva, E., L. Rolland, A. Sladen (2014), Strike-slip earthquakes can also be seen in the ionosphere. Earth and Planetary Science Letters, V.405, 180-193, doi:10.1016/j.epsl.2014.08.024.

Astafyeva, E., and K. Shults (2019) Ionospheric GNSS imagery of seismic source: possibilities, difficulties, challenges. J. Geophys. Res., V.124, N1, 534-543. Doi: 10.1029/2018JA026107.

Azeem, I., S. L. Vadas, G. Crowley, and J. J. Makela (2017), Traveling ionospheric disturbances over the United States induced by gravity waves from the 2011 Tohoku tsunami and comparison with gravity wave dissipative theory, J. Geophys. Res. Space Physics, 122, doi:10.1002/2016JA023659.

Bagiya, M.S., A. S. Sunil, P. S. Sunil, K. M. Sreejith, L. Rolland, and D. S. Ramesh (2017a), Efficiency of coseismic ionospheric perturbations in identifying crustal deformation pattern: Case study based on Mw7.3 May Nepal 2015 earthquake, J. Geophys. Res., 10.1002/2017JA024654122, 6849-6857, doi:10.1002/2017JA024050.

Bagiya, M.S., E. A. Kherani, M.S., P.S. Sunil, A.S. Sunil, S. Sunda \& Ramesh, D. S. (2017b) Origin of the ahead of tsunami traveling ionospheric disturbances during Sumatra tsunami and offshore forecasting. J. Geophys. Res., 122 (7), 7742-7749. Doi:10.1029/2017JA023971.

Bagiya, M.S., P.S. Sunil, A.S. Sunil, \& Ramesh, D. S. (2018). Coseismic contortion and coupled nocturnal ionospheric perturbations during 2016 Kaikoura, Mw7.8 New Zealand earthquake. J. Geophys. Res. Space Physics, 123, 1477-1487. doi:10.1002/2017JA024584. 
Blanc, E. (1985), Observations in the upper atmosphere of infrasonic waves from natural or artificial sources: A summary, Ann. Geophys., 3(6), 673-688.

Blanc, E., A. le Pichon, L. Ceranna, T. Farges, J. Marty, and P. Herry (2010) Global Scale Monitoring of Acoustic and Gravity waves for the study of the atmosphere dynamics. Infrasound Monitoring for Atmospheric Studies. Springer Science, Chapter 21, 647-664. DOI:10.1007/978-1-4020-9508-5_21.

Bletery, Q., A. Sladen, B. Delouis, M. Vallée, J.-M. Nocquet, L. Rolland and J. Jiang (2014). A detailed source model for the Mw9.0 Tohoku-Oki earthquake reconciling geodesy, seismology and tsunami records. J. Geophys. Res., 119, 76367653, DOI: 10.1002/2014JB011261.

Brissaud, Q., R. Martin, R. Garcia, D. Komatitsch (2016) Finite-difference numerical modelling of gravito-acoustic wave propagation in a windy and attenuating atmosphere, Geophys. J. Int, 206(1), 308-327.

Brissaud, Q., R. Martin, R. Garcia, D. Komatitsch (2017) Hybrid Galerkin numerical modelling of elastodynamics and compressible Navier-Stokes couplings: applications to seismogravito acoustic waves, Geophys. J. Int, 210 (2), 1047-1069.

Cahyadi, M. N. and K. Heki (2013). Ionospheric disturbances of the 2007 Bengkulu and the 2005 Nias earthquakes, Sumatra, observed with a regional GPS network, J. Geophys. Res., 118, 1-11, doi:10.1002/jgra.50208.

Cahyadi, M.N., and K. Heki, (2015). Coseismic ionospheric disturbance of the large strike-slip earthquakes in North Sumatra in 2012: Mw dependence of the disturbance amplitudes, Geophys. J. Int., 200, 116-129, doi: 10.1093/gji/ggu343.

Calais, E., and J.B. Minster (1995), GPS detection of ionospheric perturbations following the January 17, 1994, Northridge earthquake, Geophys. Res. Lett., 22, 1045-1048, DOI:10.1029/95GL00168.

Calais, E., Minster, J.B., Bernard, J. (1998). GPS, Earthquake, the ionosphere and Space Shuttle. Phys. Earth Planetary Interiors, 105, 167-181, doi:10.1016/s0031-9201(97)00089-7.

Calais, E., J. B. Minster, M. Hofton, M. Hedlin (1998). Ionospheric signature of surface mine blasts from Global Positioning System measurements, Geophys. J. Int., V.132, N1, 191-202. DOI: 10.1046/j.1365-246x.998.00438.x.

Caudron, C., B. Taisne, M. Garcés, L. P. Alexis, and P. Mialle (2015), On the use of remote infrasound and seismic stations to constrain the eruptive sequence and intensity for the 2014 Kelud eruption, Geophys. Res. Lett., 42, 6614-6621, doi:10.1002/2015GL064885. 
Choosakul, N., Saito, A., Iyemori, T., Hashizume, M. (2009). Excitation of 4-min pe- riodic ionospheric variations following the great Sumatra-Andaman earthquake in 2004. J. Geophys. Res. 114, A10313. Doi:10.1029/2008JA013915.

Chou, M. Y., C. C. H. Lin, J. Yue, H. F. Tsai, Y. Y. Sun, J. Y. Liu, and C. H. Chen (2017), Concentric traveling ionosphere disturbances triggered by Super Typhoon Meranti (2016), Geophys. Res. Lett., 44, 1219-1226, doi:10.1002/2016GL072205.

Chum J., Hruska F, Zednik J, Lastovicka J (2012) Ionospheric disturbances (infrasound waves) over the Czech Republic excited by the 2011 Tohoku earthquake. J. Geophys Res., 117: A08319. doi:10.1029/2012JA017767.

Chum J., J.-Y. Liu, J. Lastovicka, J. Fiser, Z. Mosna, and Y.-Y. Sun. (2016) Ionospheric signatures of the April 25, 2015 Nepal earthquake and the relative role of compression and advection for Doppler sounding of infrasound in the ionosphere. Earth Planets and Space, 68:24, DOI:10.1186/s40623-016-0401-9.

Coisson, P., P. Lognonné, D. Walwer, and L. M. Rolland (2015), First tsunami gravity wave detection in ionospheric radio occultation data, Earth and Space Science, 2, 125-133, doi:10.1002/2014EA000054.

Coster, A., J. Williams, A. Weatherwax, W. Rideout, and D. Herne (2013), Accuracy of GPS total electron content: GPS receiver bias temperature dependence, Radio Sci., 48, 190-196, doi:10.1002/rds.20011.

Crowley, G., I. Azeem, A. Reynolds, T. M. Duly, P. McBride, C. Winkler, and D. Hunton (2016), Analysis of traveling ionospheric disturbances (TIDs) in GPS TEC launched by the 2011 Tohoku earthquake, Radio Sci., 51, 507-514, doi:10.1002/2015RS005907.

DasGupta, A., A. Das, D. Hui, K. K. Bandyopadhyay, and M. R. Sivaraman (2006), Ionospheric perturbation observed by the GPS following the December 26th, 2004 Sumatra- Andaman earthquake, Earth Planets Space, 58:BF03353374, 167-172, DOI:10.1186/BF03353374.

Dautermann, T., E. Calais, and G. S. Mattioli (2009a), Global Positioning System detection and energy estimation of the ionospheric wave caused by the 13 July 2003 explosion of the Soufrière Hills Volcano, Montserrat, J. Geophys. Res., 114, B02202, doi:10.1029/2008JB005722.

Dautermann, T., E. Calais, P. Lognonné and G. S. Mattioli (2009b), Lithosphere-atmosphereionosphere coupling after the 2003 explosive eruption of the Soufriere Hills Volcano, Monserrat, Geophys. J. Int., 179, 1537-1546, doi: 10.1111/j.1365-246X.2009.04390.x.

Davies, K. and D. M. Baker, (1965) Ionospheric effects observed around the time of the Alaskan earthquake of March 28, 1964, J. Geophys. Res., 70, 2251-2253. 
959 de Angelis, S., S.R. McNutt, and P.W. Webley. (2011) Evidence of atmospheric gravity waves 960 during the 2008 eruption of Okmok volcano from seismic and remote sensing 961 observations. Geophys. Res. Lett., V. 38, L10303, doi:10.1029/2011GL047144.

962 Ducic, V., J. Artru, and P. Lognonné, (2003) Ionospheric remote sensing of the Denali 963 Earthquake Rayleigh surface waves, Geophys. Res. Lett., 30 (18), 1951, 964 doi:10.1029/2003GL017812.

965 Falck et al. (2010) Near-real time GPS applications for tsunami early warning systems. 966 Natural Hazards and Earth System Sciences, 10, 181-189, DOI: 10.5194/nhess-10-1812010.

968 Fee, D., and R. Matoza (2013). An overview of volcano infrasound: From Hawaiian to Plinian, 969 local to global. J. Volcanology and Geothermal Res., 249, 123-139.

970 Fritts, D.C., and M. Joan Alexander (2003). Gravity waves dynamics and effects in the middle 971 atmosphere. Reviews of Geophysics, 41(1), 1003, doi:10.1029/2001RG000106.

972 Fritts, D.C., and M. Joan Alexander (2012) Correction to “Gravity wave dynamics and effects in 973 the middle atmosphere", Reviews of Geophysics, 50, RG3004, DOI: $974 \quad 10.1029 / 2012$ RG000409.

975 Galvan, D. A., A. Komjathy, M. P. Hickey, and A. J. Mannucci (2011), The 2009 Samoa and 2010 976 Chile tsunamis as observed in the ionosphere using GPS total electron content, J. Geophys. 977 Res., 116, A06318, doi:10.1029/2010JA016204.

978 Galvan, D. A., A. Komjathy, M. P. Hickey, P. Stephens, J. Snively, Y. Tony Song, M. D. Butala, and 979 A. J. Mannucci (2012), Ionospheric signatures of Tohoku-Oki tsunami of March 11, 2011: 980 Model comparisons near the epicenter, Radio Sci., 47, RS4003, 981 982 983 984 985 986 987 988 989 doi:10.1029/2012RS005023.

Garcia, R. F., S. Bruinsma, P. Lognonné, E. Doornbos, and F. Cachoux (2013), GOCE: The first seismometer in orbit around the Earth, Geophys. Res. Lett., 40, doi:10.1002/grl.50205.

Garcia, R. F., E. Doornbos, S. Bruinsma, and H. Hebert (2014), Atmospheric gravity waves due to the Tohoku-Oki tsunami observed in the thermosphere by GOCE, J. Geophys. Res. Atmos., 119, doi:10.1002/2013JD021120.

Garcia et al. [2017] Finite-difference modeling of acoustic and gravity wave propagation in Mars atmosphere: application to infrasounds emitted by meteor impacts, Space Science Reviews, V. 211, N1-4, 547-570.

George, T.M. and W.H. Hooke (1970) Wave-induced fluctuations in ionospheric electron content: a model indicating some observational biases. J. Geophys. Res. - Space Phys., 75, N31, 6295-6308. 
993 Gonnermann, H.M., and M. Manga (2007) The fluid mechanics inside a volcano, Annu. Rev. $994 \quad$ Fluid. Mech., 39:321-56.

995 Grawe, M.A., \& J. J. Makela (2015), The ionospheric responses to the 2011 Tohoku, 2012 Haida 996 Gwaii, and 2010 Chile tsunamis: Effects of tsunami orientation and observation geometry, 997 Earth \& Space Science, 2(11), 472-483. 472-483, DOI: 10.1002/2015EA000132.

998 Grawe, M. A., and J. J. Makela (2016), Observation of tsunami-generated ionospheric 999 signatures over Hawaii caused by the 16 September 2015 Illapel earthquake, J. Geophys. 1000 Res. Space Physics, 122, 1128-1136, doi:10.1002/2016JA023228.

Hargreaves, J. K. (1992) The solar-terrestrial environment. An introduction to geospace - the science of the terrestrial upper atmosphere, ionosphere and magnetosphere. Cambridge University Press. 436p. Doi: 10.1017/CB09780511628924.

Heki, K. (2006), Explosion energy of the 2004 eruption of the Asama Volcano, central Japan, inferred from ionospheric disturbances, Geophys. Res. Lett., 33, L14303, doi:10.1029/2006GL026249.

Heki, K. and J. Ping (2005), Directivity and apparent velocity of the coseismic ionospheric disturbances observed with a dense GPS array, Earth Planet. Sci. Lett., 236, 845-855.

Heki, K., Y. Otsuka, N. Choosakul, N. Hemmakorn, T. Komolmis, and T. Maruyama (2006), Detection of ruptures of Andaman fault segments in the 2004 great Sumatra earthquake with coseismic ionospheric disturbances, J. Geophys. Res., 111, B09313, doi:10.1029/2005JB004202.

Hines, C.O. (1960) Internal Atmospheric Gravity Waves at Ionospheric Heights. Canadian Journal of Physics. Vol. 38, p.1441. DOI:10.1139/p60-150.

Hines, C. O. (1972), Gravity waves in the atmosphere, Nature, 239, 73-78, doi:10.1038/239073a0.

Hofmann-Wellenhof, B., H. Lichtenegger, and E. Wasle (2008) GNSS-Global Navigation Satellite Systems, Springer, doi:10.1007/978-3-211-73017-1.

Huang, C.Y., J.F. Helmboldt, J. Park, T.R. Pedersen, R. Willemann. (2019) Ionospheric detection of explosive events. Reviews of Geophysics, 57, 78-105, doi:10.1029/2017RG000594.

Huba, J. D., Drob, D. P., Wu, T.-W., \& Makela, J. J. (2015). Modeling the ionospheric impact of tsunami-driven waves with SAMI3: Conjugate effects. Geophysical Research Letters, 42, 5719-5726. DOI: 10.1002/2015GL064871.

Jin, S., G. Occhipinti, R. Jin (2015) GNSS ionospheric seismology: Recent observation evidences and characteristics, Earth-Science Rev., 147, 54064, DOI :10.1016/j.earthscirev.2015.05.003. 
1027

1028

1029

1030

1031

1032

1033

1034

1035

1036

1037

1038

1039

1040

1041

1042

1043

1044

1045

1046

1047

1048

1049

1050

1051

1052

1053

1054

1055

1056

1057

1058

1059

1060

Jin, S., R. Jin, and J. H. Li (2014), Pattern and evolution of seismo-ionospheric disturbances following the 2011 Tohoku earthquakes from GPS observations, J. Geophys. Res. Space Physics, 119, 7914-7927, doi:10.1002/2014JA019825.

Jin, S., R. Jin, and D. Li (2017), GPS detection of ionospheric Rayleigh wave and its source following the 2012 Haida Gwaii earthquake, J. Geophys. Res., 122, 1360-1372, doi:10.1002/2016JA023727.

Jin, S.. (2018) Two-mode ionospheric disturbances following the 2005 Northern California offshore earthquake from GPS measurements, J. Geophys. Res., doi:10.1029/2017JA025001.

Kakinami, Y. et al. (2012) Tsunamigenic ionospheric hole, Geophys. Res. Lett., 39, L00G27, doi:10.1029/2011GL050159.

Kakinami, Y., M. Kamogawa, S. Watanabe, M. Odaka, T. Mogi, J.-Y. Liu, Y.-Y. Sun, and T. Yamada (2013), Ionospheric ripples excited by superimposed wave fronts associated with Rayleigh waves in the thermosphere, J. Geophys. Res. Space Physics, 118, doi:10.1002/jgra.50099.

Kamogawa, M. et al. (2015), Does an ionospheric hole appear after an inland earthquake?, J. Geophys. Res. Space Physics, 120, 9998-10,005, doi:10.1002/2015JA021476.

Kamogawa, M. et al. (2016) A possible space-based tsunami early warning system using observations of the tsunami ionospheric hole. Sci. Rep., 6:37989, doi:10.1038/srep37989.

Kanamori, H., J. Mori (1992). Harmonic excitation of mantle Rayleigh waves by the 1991eruption of Mount Pinatubo, Philippines, Geophys. Res. Lett., 19(7) 721-724, DOI: 10.1029/92GL00258.

Kanamori, H., J. Mori, and D.G. Harkrider (1994). Excitation of atmospheric oscillations by volcanic eruptions. J. Geophys. Res., V. 99, B11, 21,947-21,961, doi: 10.1029/94JB01475.

Kherani, E.A., Lognonné, P., Kamath, N., Crespon, F. \& Garcia, R. (2009). Response of the ionosphere to the seismic triggered acoustic waves: electron density and electromagnetic fluctuations, Geophys J. Int., 176, 1-13, doi:10.1111/j.1365-246X.2008.03818.x.

Kherani, E.A. et al. (2012). Modelling of the Total Electronic Content and magnetic field anomalies generated by the 2011 Tohoku-oki tsunami and associated acoustic-gravity waves, Geophys. J. International, doi:10.1111/j.1365-246X.2012.05617.x.

Kiryushkin, V.V. and E.L. Afraimovich (2007) Determining the Parameters of Ionospheric Perturbation Caused by Earthquakes Using the Quasi-Optimum Algorithm of Spatiotemporal Processing of TEC Measurements, Earth Planets Space, 2007, vol. 59, pp. 267-278. 
1061 Kiryushkin, V.V., E.L. Afraimovich, E.I. Astafyeva (2011) The evolution of seismo-ionospheric

1062

1063

1064

1065

1066

1067

1068

1069

1070

1071

1072

1073

1074

1075

1076

1077

1078

1079

1080

1081

1082

1083

1084

1085

1086

1087

1088

1089

1090

1091

1092

1093

1094 disturbances according to the data of dense GPS network. Cosmic Research, V. 49, No.3, 227-239, doi: 10.1134/S0010952511020043.

Komjathy, A., Galvan, D.A., Stephens, P. et al. (2012) Detecting ionospheric TEC perturbations caused by natural hazards using a global network of GPS receivers: The Tohoku case study, Earth Planets Space, V.64, 24. doi:10.5047/eps.2012.08.003.

Komjathy, A., Y.-M. Yang, X. Meng, O. Verkhoglyadova, A. J. Mannucci, and R. B. Langley (2016), Review and perspectives: Understanding natural-hazards-generated ionospheric perturbations using GPS measurements and coupled modeling, Radio Sci., 51, 951-961, doi:10.1002/2015RS005910.

Krasnov VM, Drobzheva Y, Lastovicka J (2007) Acoustic energy transfer to the upper atmosphere from sinusoidal sources and a role of non-linear processes. J Atmos Sol Terr Phys 69:1357-1365.

LaBreque, J., J. Rundle, G. Bawden (2017) Global Navigation Satellite Systems to enhance tsunami warning systems. GNSS Tsunami Early Warning System Workshop 2017, Report. https://apru.org/gnss-tsunami-early-warning-system-report/

Lee, R.F., L.M. Rolland, T.D. Mykesell (2018) Seismo-ionospheric observations, modeling and backprojection of the 2016 Kaikoura earthquake. Bulletin of the Seismological Society of America, DOI:10.1785/0120170299.

Leonard, R. S., and R. A. Barnes, Jr., (1965) Observation of ionospheric disturbances following the Alaskan earthquake, J. Geophys. Res., 70(5), 1250-1253.

Li, J., C.M. Rude, V. Pankratius (2019) Characterizing the Complex Two N-wave ionospheric signature of the 2016 Kaikoura Earthquake. J. Geophys. Res., V.122, doi:10.1029/2018JA025376.

Liu, J. Y. et al. (2006a), Giant ionospheric disturbances excited by the M9.3 Sumatra earthquake of 26 December 2004, Geophys. Res. Lett., 33, L02103, doi:10.1029/2005GL023963

Liu, J. Y., et al. (2006b), Ionospheric GPS total electron content (TEC) disturbances triggered by the 26 December 2004 Indian Ocean tsunami, J. Geophys. Res., 111, A05303

Liu, J. Y., et al. (2010), Coseismic ionospheric disturbances triggered by the Chi-Chi earthquake, J. Geophys. Res., 115, A08303, doi:10.1029/2009JA014943.

Liu, J. Y., C.H. Chen, C.H. Lin, H.F. Tsai, C.H. Chen, and M. Kamogawa (2011), Ionospheric disturbances triggered by the 11 March 2011 M9.0 Tohoku earthquake, J. Geophys. Res., 116, A06319, doi:10.1029/2011JA016761. 
1095

1096

1097

1098

1099

1100

1101

1102

1103

1104

1105

1106

1107

1108

1109

1110

1111

1112

1113

1114

1115

1116

1117

1118

1119

1120

1121

1122

1123

1124

1125

1126

1127

1128

Liu, X., Q. Zhang, M. Shah, Z. Hong (2017) Atmospheric-ionospheric disturbances following the April 2015 Calbuco volcano from GPS and OMI observations. Advances in Space Research, 60, 2836-2846.

Lognonné, P., E. Clévédé, and H. Kanamori (1998), Computation of seismograms and atmospheric oscillations by normal-mode summation for a spherical earth model with realistic atmosphere, Geophys. J. Int., 135, 388-406, doi:10.1046/j.1365246X.1998.00665.X.

Lognonné, P., J. Artru, R. Garcia, F. Crespon, V. Ducic, E. Jeansou, G. Occhipinti, J. Helbert, G. Moreaux, and P. E. Godet (2006), Ground based GPS imaging of ionospheric post-seismic signal, Planet. Space Sci., 54, 528-540.

Makela, J.J. et al (2011) Imaging and modeling the ionospheric airglow response over Hawaii to the tsunami generated by the Tohoku Earthquake of 11 March 2011, Geophys. Res. Lett., 38, L00G02, doi:10.1029/2011GL047860.

Maruyama T., Shinagawa H. (2014) Infrasonic sounds excited by seismic waves of the 2011 Tohoku-oki earthquake as visualized in ionograms. J Geophys Res Space Phys 119:40944108. doi:10.1002/2013JA019707.

Maruyama T., Shinagawa H., K. Yusupov, and A. Akchurin. (2017) Sensitivity of ionosonde detection of atmospheric disturbances induced by seismic Rayleigh waves at different latitudes. Earth Planets Space, 69:20, DOI 10.1186/s40623-017-0600-z.

Matoza, R. et al. (2011) Infrasonic observations of the June 2009 Sarychev Peak eruption, Kuril Islands: Implications for infrasonic monitoring of remote explosive volcanism, Journal of Volcanology and Geothermal Research, 200, 35-48, doi:10.1016/j.jvolgeores.2010.11.022.

Matoza, R., et al (2018) Local, Regional, and Remote Seismo-acoustic Observations of the April 2015 VEI 4 Eruption of Calbuco Volcano, Chile. J. Geophys. Res. Soli Earth, V. 123, N5, 38143827, doi: 10.1002/2017JB015182.

Meng, X., A. Komjathy, O. P. Verkhoglyadova, Y.-M. Yang, Y. Deng, and A. J. Mannucci (2015), A new physics-based modeling approach for tsunamiionosphere coupling, Geophys. Res. Lett., 42, 4736-4744, doi:10.1002/2015GL064610.

Meng, X., O.P Verkhoglyadova, A. Komjathy, G. Savastano, and A. Mannucci (2018) PhysicsBased Modeling of Earthquake-Induced Ionospheric Disturbances, J. Geophys. Res., V. 123, N9, 8021-8038, doi: 10.1029/2018JA025253.

Miller, S.D., W.C. Straka, J. Yue, S.M. Smith, M.J. Alexander, L. Hoffmann, M. Setval, and P.T. Partain. Upper atmospheric gravity wave details revealed in nightglow satellite imagery. 
Proceedings of the National Academy of Sciences of the USA (PNAS), V.112, N.49, E67286735, doi:10.1073/pnas.1508084112.

Najita, K., P.F. Weaver, P.C. Yuen (1974) A tsunami warning system using an ionospheric technique, Proceedings of the IEEE, V.62, N5, 563-577, DOI :10.1109/PROC.1974.9480.

Nakashima, Y., K. Heki, A. Takeo, M.N. Cahyadi, A. Aditiya, K. Yoshizawa. (2016) Atmospheric resonant oscillations by the 2014 eruption of the Kelud volcano, Indonesia, observed with the ionospheric total electron contents and seismic signals. Earth and Planetary Science Letters, V. 434, 112-116, doi:10.1016/j.epsl.2015.11.029.

Naugolnykh, K., and L. Ostrovsky (1998) Nonlinear Wave Processes in Acoustics. Cambridge University Press, 297p.

Nishioka, M., T. Tsugawa, M. Kubota, and M. Ishii (2013), Concentric waves and short-period oscillations observed in the ionosphere after the 2013 Moore EF5 tornado, Geophys. Res. Lett., 40, 5581- 5586, doi:10.1002/2013GL057963.

Occhipinti, G., P. Lognonné, E. A. Kherani, and H. Hébert (2006), Three-dimensional waveform modeling of ionospheric signature induced by the 2004 Sumatra tsunami, Geophys. Res. Lett., 33, L20104, doi:10.1029/2006GL026865.

Occhipinti, G., E. A. Kherani, and P. Lognonné (2008), Geomagnetic dependence of ionospheric disturbances induced by tsunamigenic internal gravity waves, Geophys. J. Int., 173, 753765, doi:10.1111/j.1365-246X.2008.03760.x.

Occhipinti, G., P. Coïsson, J. J. Makela, S. Allgeyer, A. Kherani, H. Hebert, and P. Lognonné (2011), Three-dimensional numerical modeling of tsunami-related internal gravity waves in the Hawaiian atmosphere, Earth Planet, Science, 63 (7), 847-851, doi:10.5047/eps.2011.06.051.

Occhipinti, G., L. Rolland, P. Lognonné and S. Watada (2013), From Sumatra 2004 to TohokuOki 2011: The systematic GPS detection of the ionospheric signature induced by tsunamigenic earthquakes, J. Geophys. Res. Space Physics, 118, doi:10.1002/jgra.50322.

Occhipinti, G. (2015) The Seismology of the Planet Mongo: The 2015 Ionospheric Seismology Review, AGU Books, Subduction Dynamics: From Mantle to Mega Disasters, Editors: G. Morra, D. A. Yuen, S. King, S. M. Lee, S. Stein, ISBN 978-1-118-88885-8.

Occhipinti, G., et al. (2018) Surface waves magnitude estimation from ionospheric signature of Rayleigh waves measured by Doppler sounder and OTH radar, Sci. Rep., 8:1555, DOI:10.1038/s41598-018-19305-1.

Otsuka, Y. et al. (2006) GPS detection of total electron content variations over Indonesia and Thailand following the 26 December 2004 Earthquake. Earth Planets Space, 58, 159-165. 
1163 Peltier, W. R., and C. O. Hines (1976), On the possible detection of tsunamis by a monitoring of the ionosphere, J. Geophys. Res., 81(12), 1995-2000.

Perevalova, N.P., V.A. Sankov, E.I. Astafyeva, A.S. Zhupityaeva (2014). Threshold magnitude for ionospheric response to earthquakes, J. Atmos. Solar-Terr. Physics, V.108, p.77-90, doi:10.1016/j.jastp.2013.12.014.

Pokhotelov, O.A., M. Parrot, V.A Pilipenko, E.N. Fedorov, V.V. Surkov, V.A. Gladyshev (1995) Response of the ionosphere to natural and man-made acoustic sources, Ann. Geophysicae, 13, 1197-1210.

Rakoto, V., P. Lognonné, L. Rolland (2017). Tsunami modeling with Solid Earth -atmosphere coupled normal modes. Geophys. J. Int., ggx322, doi:10.1093/gji/ggx322.

Rakoto, V., P. Lognonné, L. Rolland, P. Coisson (2018). Tsunami wave height estimation from GPS-derived ionospheric data. J. Geophys. Res., V.123, 4329-4348. DOI :10.1002/2017JA024654

Reddy, C. D., and G. K. Seemala (2015), Two-mode ionospheric response and Rayleigh wave group velocity distribution reckoned from GPS measurement following Mw 7.8 Nepal earthquake on 25 April 2015, J. Geophys. Res. Space Physics, 120, 7049-7059, doi:10.1002/2015JA021502.

Ridley, A. J., Y. Deng, and G. Tóth (2006), The Global Ionosphere-Thermosphere Model, J. Atmos. Sol. Terr. Phys., 68, 839-864, doi:10.1016/j.jastp.2006.01.008.

Ripepe, M., S. De Angelis, G. Lacanna, and B. Voight (2010), Observation of infrasonic and gravity waves at Soufrière Hills Volcano, Montserrat, Geophys. Res. Lett., 37, L00E14, doi:10.1029/2010GL042557.

Rolland, L. M., G. Occhipinti, P. Lognonné, and A. Loevenbruck (2010), Ionospheric gravity waves detected offshore Hawaii after tsunamis, Geophys. Res. Lett., 37, L17101, doi:10.1029/2010GL044479

Rolland, L., P. Lognonné, H. Munekane (2011a), Detection and modeling of Rayleigh wave induced patterns in the ionosphere, J. Geophys. Res., V.116, A05320, doi:10.1029/2010JA016060.

Rolland, L., Lognonné, P., Astafyeva, E., Kherani, A., Kobayashi, N., Mann, M., Munekane, H. (2011b). The resonant response of the ionosphere imaged after the 2011 Tohoku-oki earthquake. Earth Planets Space, 63 (7). DOI:10.5047/eps.2011.06.020.

Rolland, L. M., M. Vergnolle, J.-M. Nocquet, A. Sladen, J.-X. Dessa, F. Tavakoli, H.R. Nankali, and F. Cappa (2013), Discriminating the tectonic and non-tectonic contributions in the 
ionospheric signature of the 2011, Mw7.1, dip-slip Van earthquake, Eastern Turkey, Geophys. Res. Lett., 40, doi:10.1002/grl.50544.

Saito, A. et al. (2011) Acoustic resonance and plasma depletion detected by GPS total electron content observation after the 2011 off the Pacific coast of Tohoku earthquake. Earth Planets Space, 63(7), 863-867, DOI: 10.5047/eps.2011.06.034.

Savastano, G., A. Komjathy, O. Verkhoglyadova, A. Mazzoni, M. Crespi, Y. Wei, and A. Mannucci. (2017), Real-time detection of tsunami ionospheric disturbances with a stand-alone GNSS-receiver: a prelim feasibility demonstration. Sci. Reports, 7:46607, DOI:10.1038/srep46607.

Simons et al. (2011) The 2011 magnitude 9.0 Tohoku-oki earthquake: Mosaicking the megathrust from seconds to centuries, Science, 332(6036), 1421-1425, doi:10.1126/science.1206731.

Shinagawa, H., T. Tsugawa, M. Matsumura, T. Iyemori, A. Saito, T. Maruyama, H. Jin, M. Nishioka, and Y. Otsuka (2013), Two-dimensional simulation of ionospheric variations in the vicinity of the epicenter of the Tohoku-oki earthquake on 11 March 2011, Geophys. Res. Lett., 40, 5009-5013, doi:10.1002/2013GL057627.

Shults, K., E. Astafyeva and S. Adourian (2016). Ionospheric detection and localization of volcano eruptions on the example of the April 2015 Calbuco events. J. Geophys. Res. -Space Physics, V.121, N10, 10,303-10,315, doi:10.1002/2016JA023382.

Sun, Y.-Y., J.-Y. Liu, C.-Y. Lin, H.-F. Tsai, L. C. Chang, C.-Y. Chen, and C.-H. Chen (2016), Ionospheric F2 region perturbed by the 25 April 2015 Nepal earthquake, J. Geophys. Res. Space Physics, 121, 5778-5784, doi:10.1002/2015JA022280.

Thomas, D., M.S. Bagiya, P.S. Sunil, L. Rolland, A.S. Sunil, T.D. Mikesell, S. Nayak, S. Subrahmanyam, D. S. Ramesh (2018) Revelation of early detection of co-seismic ionospheric perturbations in GPS-TEC from realistic modelling approach: Case study, Sci. Rep., 8:12105, DOI:10.1038/s41598-018-30476-9.

Tsai, H.-F., J.-Y. Liu, C.-H. Lin, and C.-H. Chen. (2011) Tracking the epicenter and the tsunami origin with GPS ionosphere observation. Earth Planets Space, 63, 859-862.

Tsugawa, T. et al (2011) Ionospheric disturbances detected by GPS total electron content observation after 2011 off the Pacific coast of Tohoku earthquake. Earth Planets Space, 63:66, DOI: 10.5047/eps.2011.06.035.

Tulasi Ram, S., Sunil, P. S., Ravi Kumar, M., Su, S.-Y., Tsai, L. C., \& Liu, C. H. (2017). Coseismic traveling ionospheric disturbances during the Mw 7.8 Gorkha, Nepal, Earthquake on 25 
April 2015 from ground and space-borne observations. Journal of Geophysical Research, 122, 10,669-10,685. DOI :10.1002/2017JA023860.

1231 Yang, Y.-M., X. Meng, A. Komjathy, O. Verkholyadova, R. B. Langley, B. T. Tsurutani, and A. J. Mannucci (2014), Tohoku-Oki earthquake caused major ionospheric disturbances at 450 km altitude over Alaska, Radio Sci., 49, 1206-1213, doi:10.1002/2014RS005580.

Yang, Y.-M., O. Verkhoglyadova, M. G. Mlynczak, A. J. Mannucci, X. Meng, R. B. Langley, and L. A. Hunt (2017), Satellite-based observations of tsunami-induced mesosphere airglow perturbations, Geophys. Res. Lett., 44, 522-532, doi:10.1002/2016GL070764.

Zel'dovich, Ya. B. and Yu. P. Raizer (2002). Physics of Shock Waves and High-Temperature Hydrodynamic Phenomena. V.1. Academic Press, NY \& London. 464 pp.

Zettergren, M., and J. B. Snively (2015), Ionospheric response to infrasonic-acoustic waves generated by natural hazard events, J. Geophys. Res. Space Physics, 120, 8002-8024, doi:10.1002/2015JA021116.

Zettergren, M. D., J. B. Snively, A. Komjathy, and O. P. Verkhoglyadova (2017), Nonlinear ionospheric responses to large-amplitude infrasonic-acoustic waves generated by undersea earthquakes, J. Geophys. Res. Space Physics, 122, 2272-2291, doi:10.1002/2016JA023159

1246 


\begin{tabular}{|c|c|c|c|c|c|}
\hline $10^{-6}$ & $10^{-4}$ & $10^{-2}$ & $10^{\circ}$ & $10^{2}$ & $10^{4}$ Frequency $(\mathrm{Hz})$ \\
\hline
\end{tabular}

\section{Gravity waves}

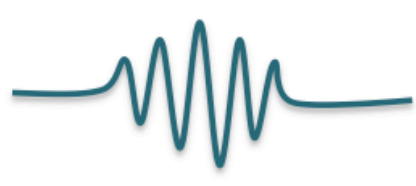

1264

126

1266

1267

1268

1269

1270

1271

1272 only propagate horizontally.

\section{Acoustic waves}

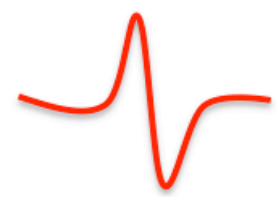

Infrasound

1s

\section{$0.05 \mathrm{~s}$}

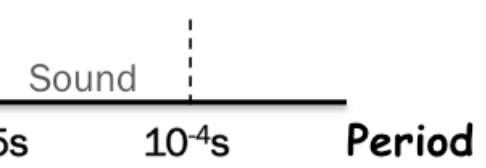

Figure 1. Frequency and period ranges for acoustic and gravity waves. The frequency $\omega_{a}$ is commonly called "the acoustic cut-off frequency" indicating that acoustic waves with $\omega>\omega_{a}$ propagate through the atmosphere. The frequency $\omega_{b}$ is the Brunt-Väissälä frequency (or buoyancy frequency). Waves with frequencies below the $\omega_{b}$ are the gravity waves. In the lower atmosphere, the acoustic cut-off frequency is typically $3.3 \mathrm{mHz}$ and $\omega_{\mathrm{b}}$ is $2.9 \mathrm{mHz}$. Waves with frequencies $\omega_{b}<\omega<\omega_{a}$ (shaded rectangle) are called evanescent waves and can 


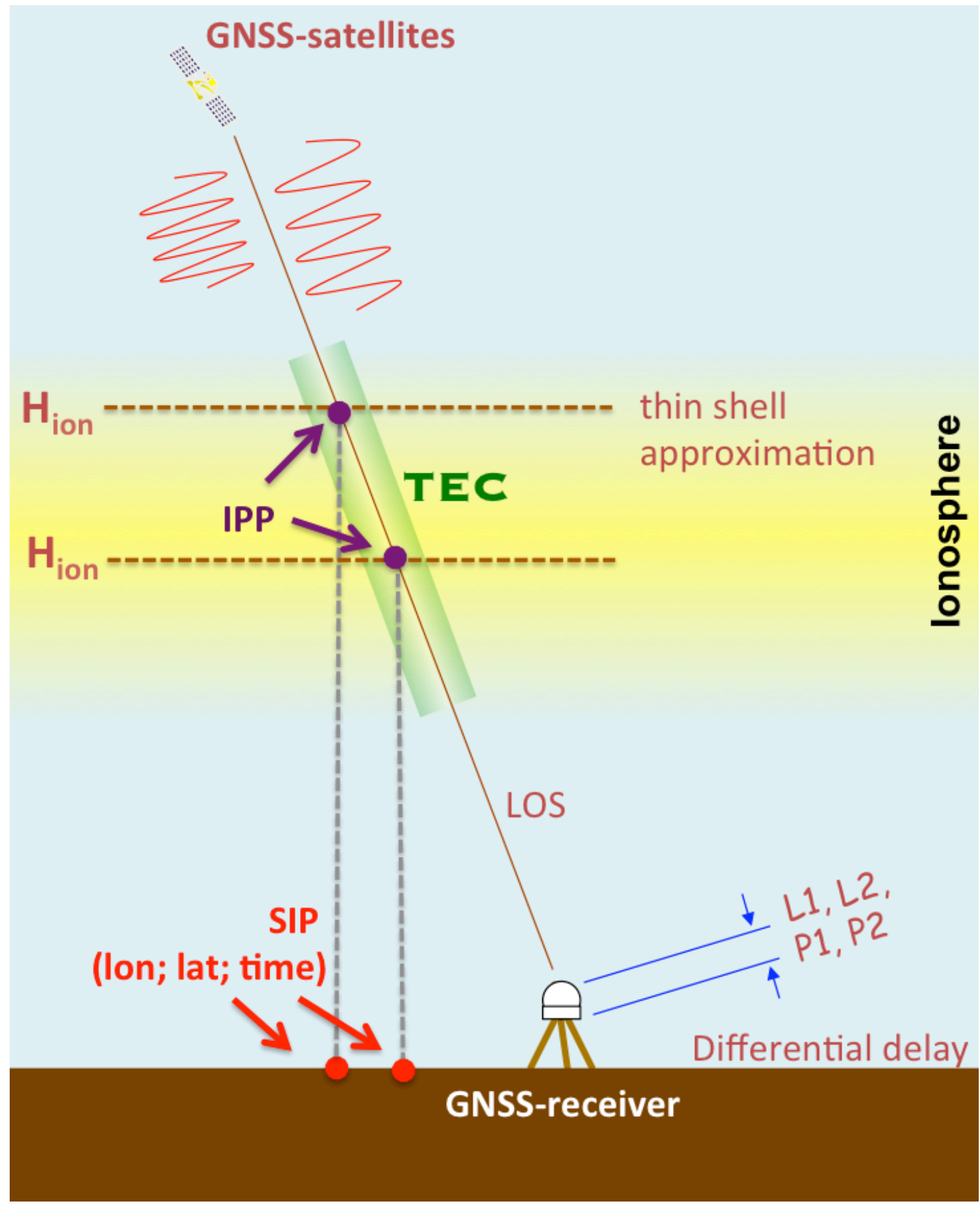

1275 Figure 2. GNSS-sounding of the ionosphere. LOS = line-of-sight between a GNSS satellite and 1276 a GNSS receiver; IPP=Ionospheric Piercing Point, the intersection point between the LOS and 1277 the altitude of the ionosphere $\left(H_{i o n}\right)$ within a thin shell approximation; SIP = the projection of 1278 the IPP on the Earth's surface. Knowing the coordinates of a satellite and a receiver one can 1279 calculate the coordinates of the SIP. Note that changing the altitude $H_{\text {ion }}$ will change the 1280 coordinates of the SIP. 


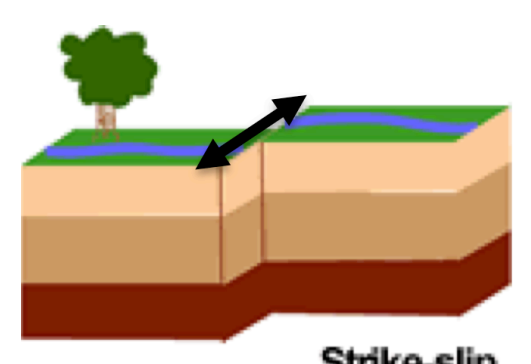

Strike-slip

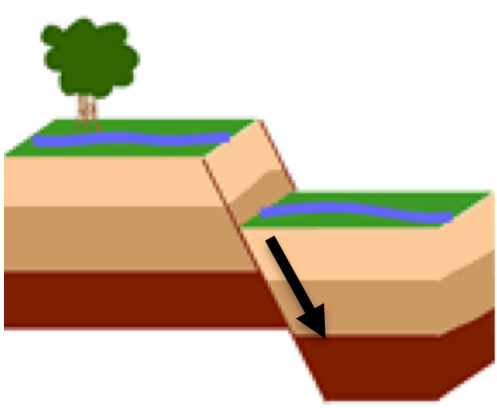

Nomal

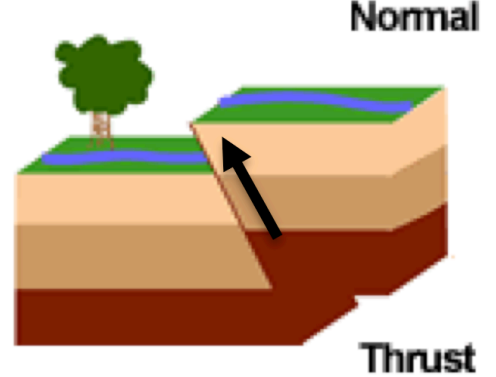

1282 Figure 3. Schematic view of the three main types of focal mechanisms: strike-slip (mostly 1283 horizontal motion), normal (mostly subsidence) and thrust (mostly uplift). Black arrows show 1284 the main direction of co-seismic crustal motion. [Image credit: U.S. Geological Survey, 1285 earthquake.usgs.gov.] 


\section{Co-Seismic \& Co-Tsunamic Ionospheric Disturbances}

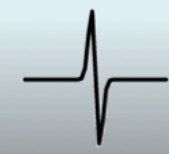

$\sim 8 \min +$

1
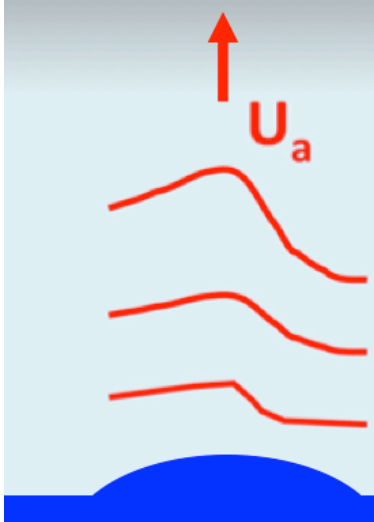

$\uparrow$

Earthquake
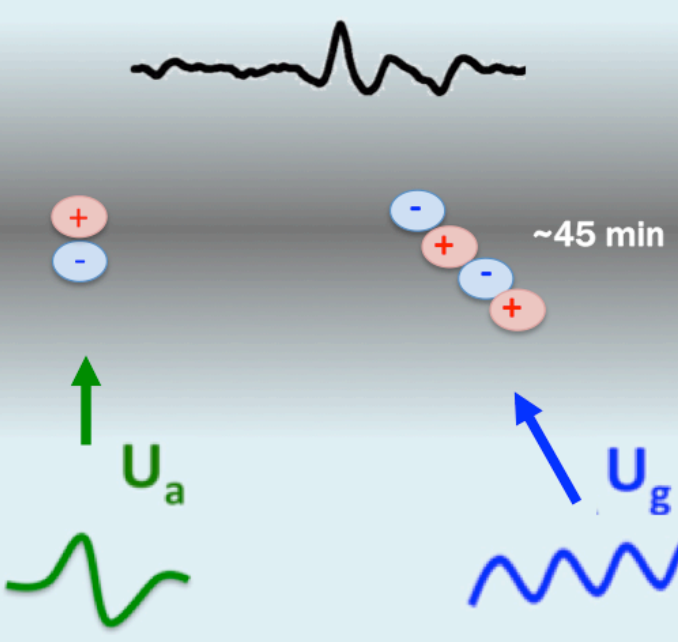

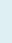
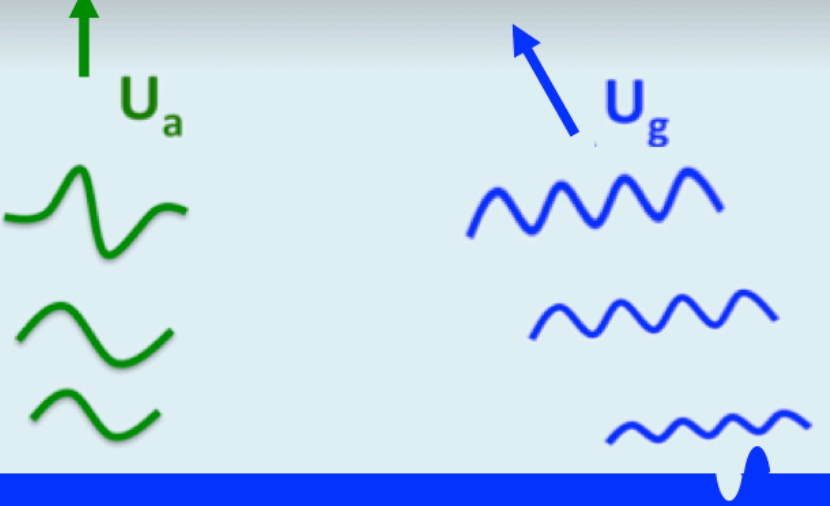

tsunami

Rayleigh surface wave

Figure 4. Scheme showing the dynamic coupling between co-seismic crustal motion, Rayleigh surface waves, tsunami propagation, and the ionosphere. The acoustic waves (Ua) generated by an earthquake and by Rayleigh surface waves propagate upward and reach the ionosphere in $\sim 8 \mathrm{~min}$. Tsunamis generate gravity waves (Ug) that propagate obliquely and reach the ionosphere in $\sim 45-60 \mathrm{~min}$. Both acoustic and gravity waves are amplified with the altitude because of the exponential decrease of the atmospheric density with height. 

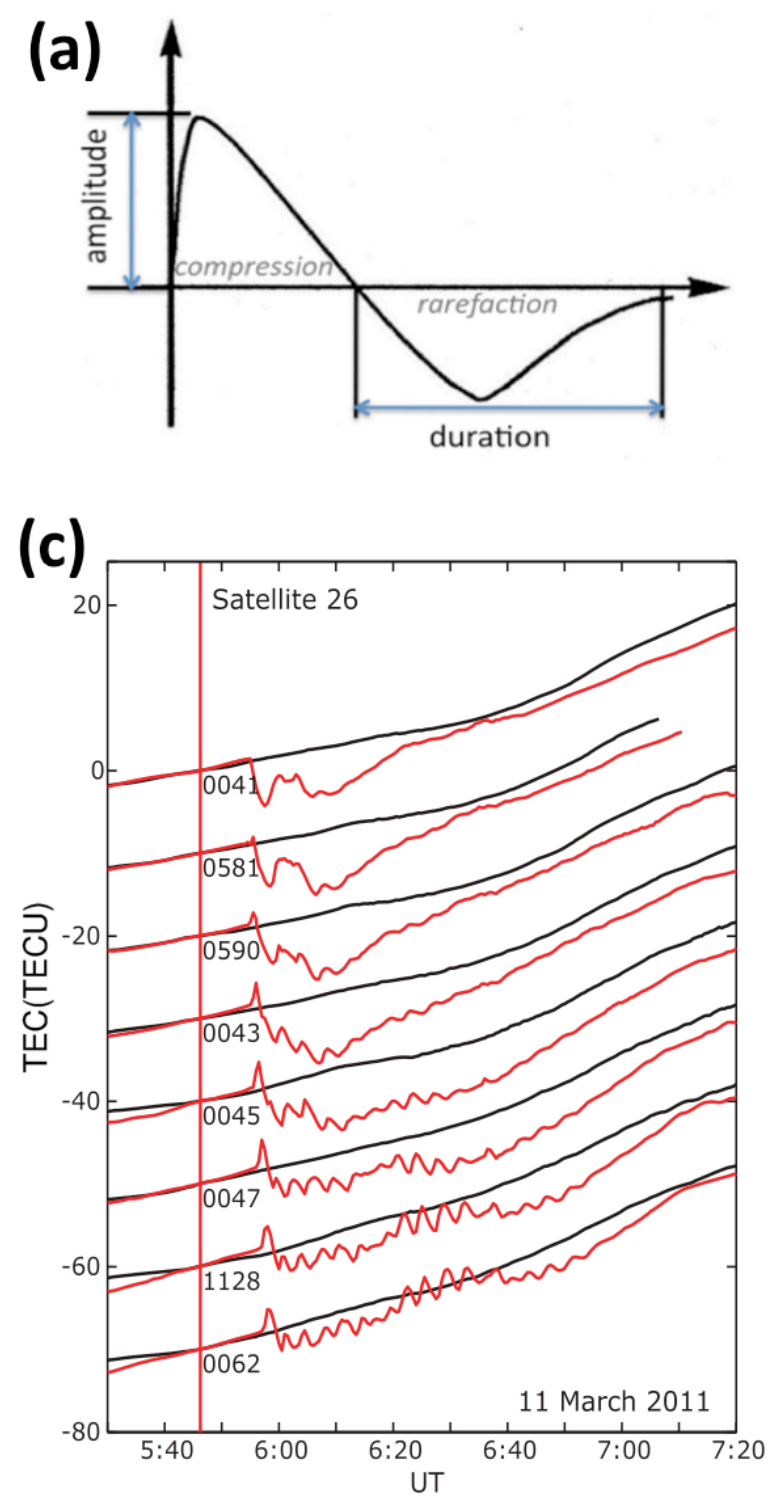
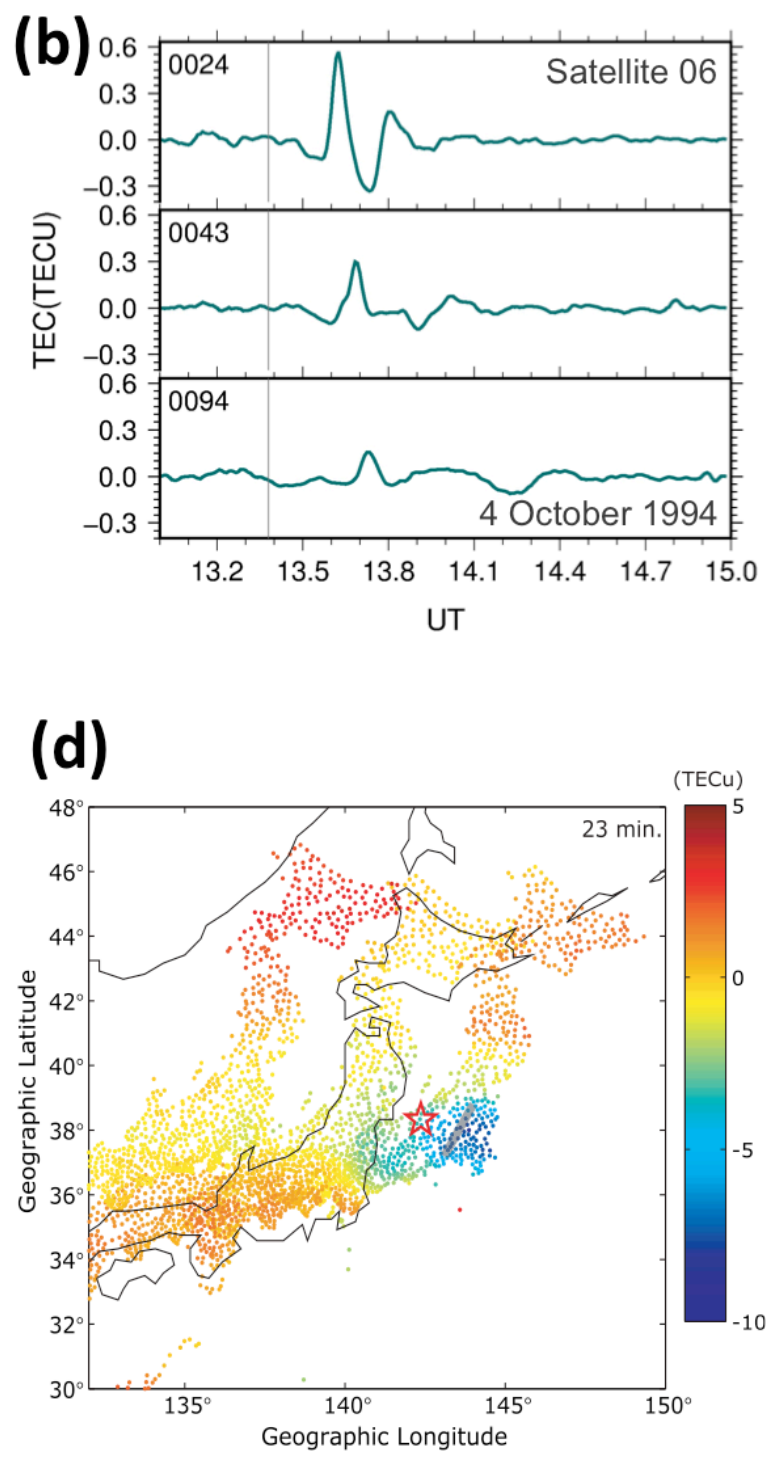

Figure 5. Typical waveforms of ionospheric perturbations generated by earthquakes: (a) theoretical $\mathrm{N}$-wave produced by a piston-like motion due to sudden crustal motion [from Astafyeva et al., 2013]; (b) example of CSID recorded by GPS-receivers 0024, 0043 and 0094 after the Mw=8.3 Kuril earthquake of 4 October 1994. Time of earthquake 13.38UT is shown by a gray thin vertical line; (c) TEC time series for the day of the Tohoku-oki earthquake (red curves) and for the reference day (black curve). A vertical solid line indicates the time of the mainshock at 5:46UT. Each TEC curve is drawn with shifting by 10 TECU. One can clearly see a strong TEC decrease as compared to the reference values; (d) Occurrence of the TEC depletion (ionospheric hole) detected over the epicentral area $23 \mathrm{~min}$ after the Tohoku-oki earthquake [Panels (c-d) are from Kakinami et al., 2012]. 


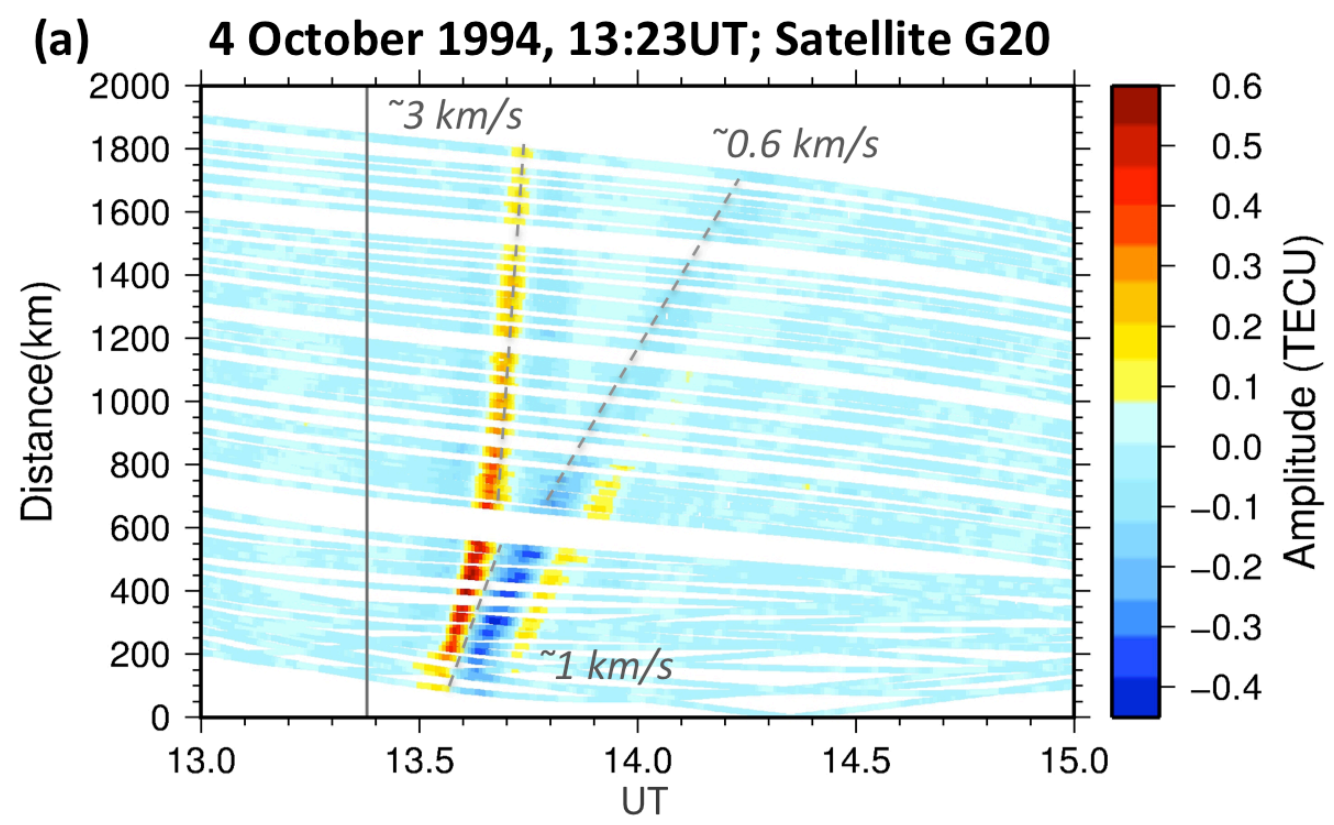

(b) 11 March 2011, 05:46UT; Satellite G15

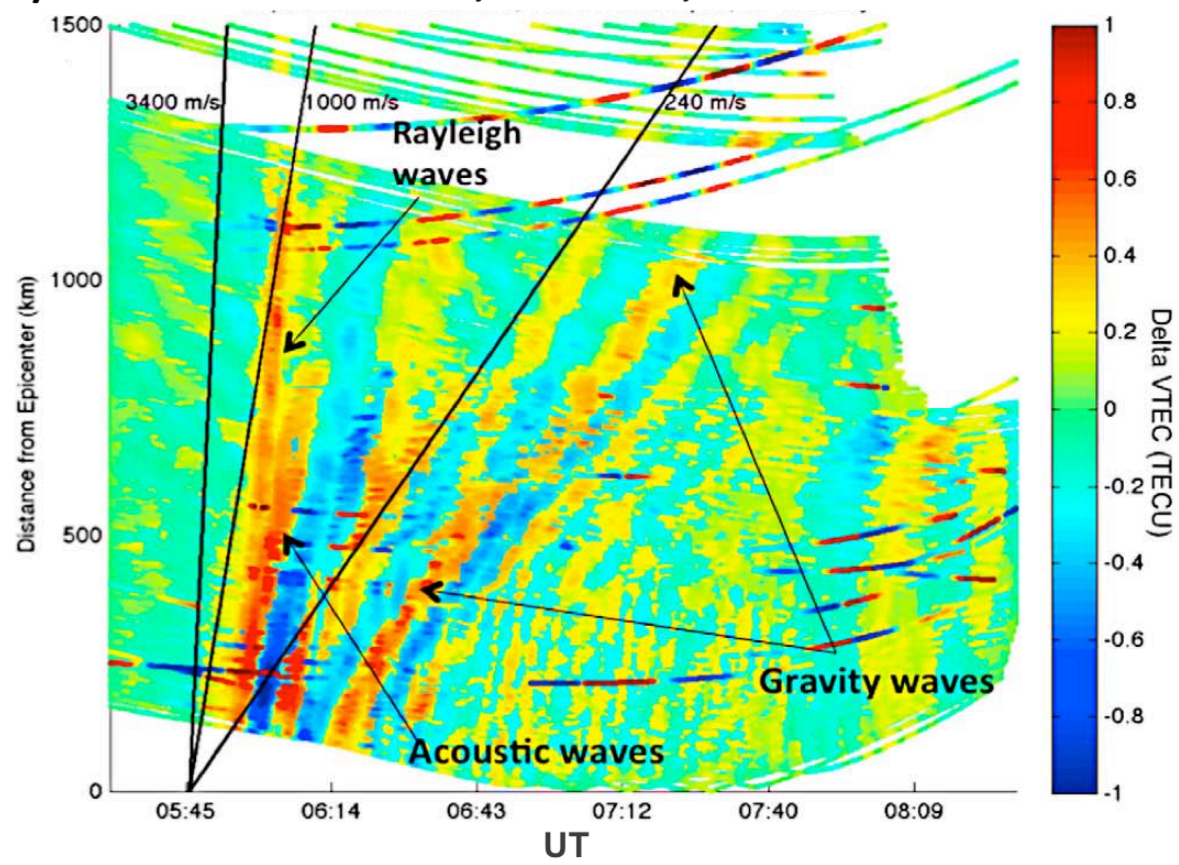

1307 Figure 6. (a) Travel-time diagram (TTD) for the case of co-seismic ionospheric perturbations

1308 following the M8.3 earthquake that occurred on 4 October 1994 in the vicinity of the Kuril

1309 Islands. The TEC observations are from GPS-satellite G20 and 100 ground-based GPS-

1310 receivers of the Japanese Network GEONET. The color shows the TEC amplitude, the 1311 corresponding color scale is shown on the right. In the near-field, we observe one CID with 1312 propagation speed of $\sim 1 \mathrm{~km} / \mathrm{s}$, starting from $600 \mathrm{~km}$ away from the epicenter, the CID splits 1313 into two modes, the one (fast mode) continues to propagate at $\sim 3 \mathrm{~km} / \mathrm{s}$, whereas the other 1314 (slower mode) goes at $600 \mathrm{~m} / \mathrm{s}$; (b) TTD showing the occurrence of multi-mode ionospheric 1315 perturbations observed after the 11 March $2011 \mathrm{Mw}=9.1$ Tohoku-oki earthquake. The TEC 
1316 observations are from satellite G15 and 1200 GPS-receivers of the GEONET. From the estimated velocities, we conclude that after the Tohoku-oki earthquake we observe Rayleigh waves, acoustic waves, gravity waves due to the tsunami. The velocities of these components

1319 are indicated on the panel [Panel (b) is adapted from Galvan et al., 2012]
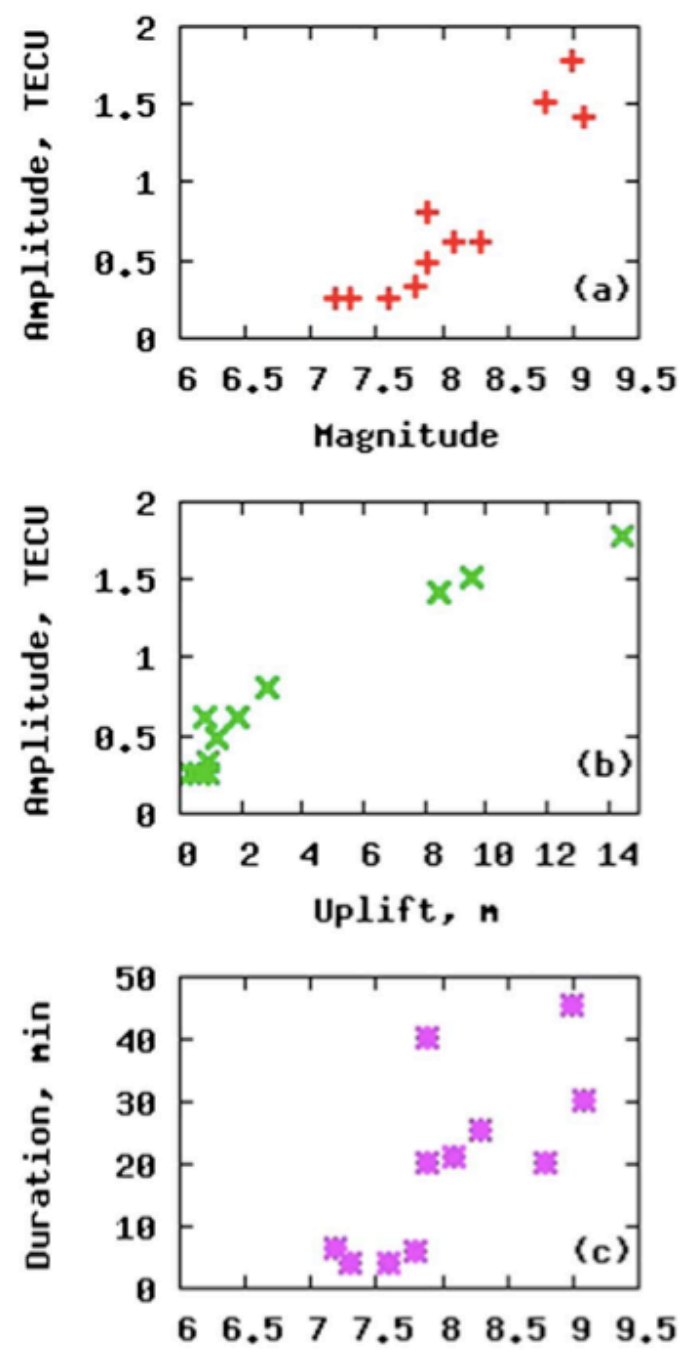
Magnitude

1324 Figure 7. (a-b) Dependence of the amplitude of the near-field CSID on the magnitude of 1325 earthquakes (a) and on the magnitude of co-seismic uplift (b). (c) Duration of the negative 1326 phase of the TEC response versus EQ's magnitude. [Adapted from Astafyeva et al., 2013a] 

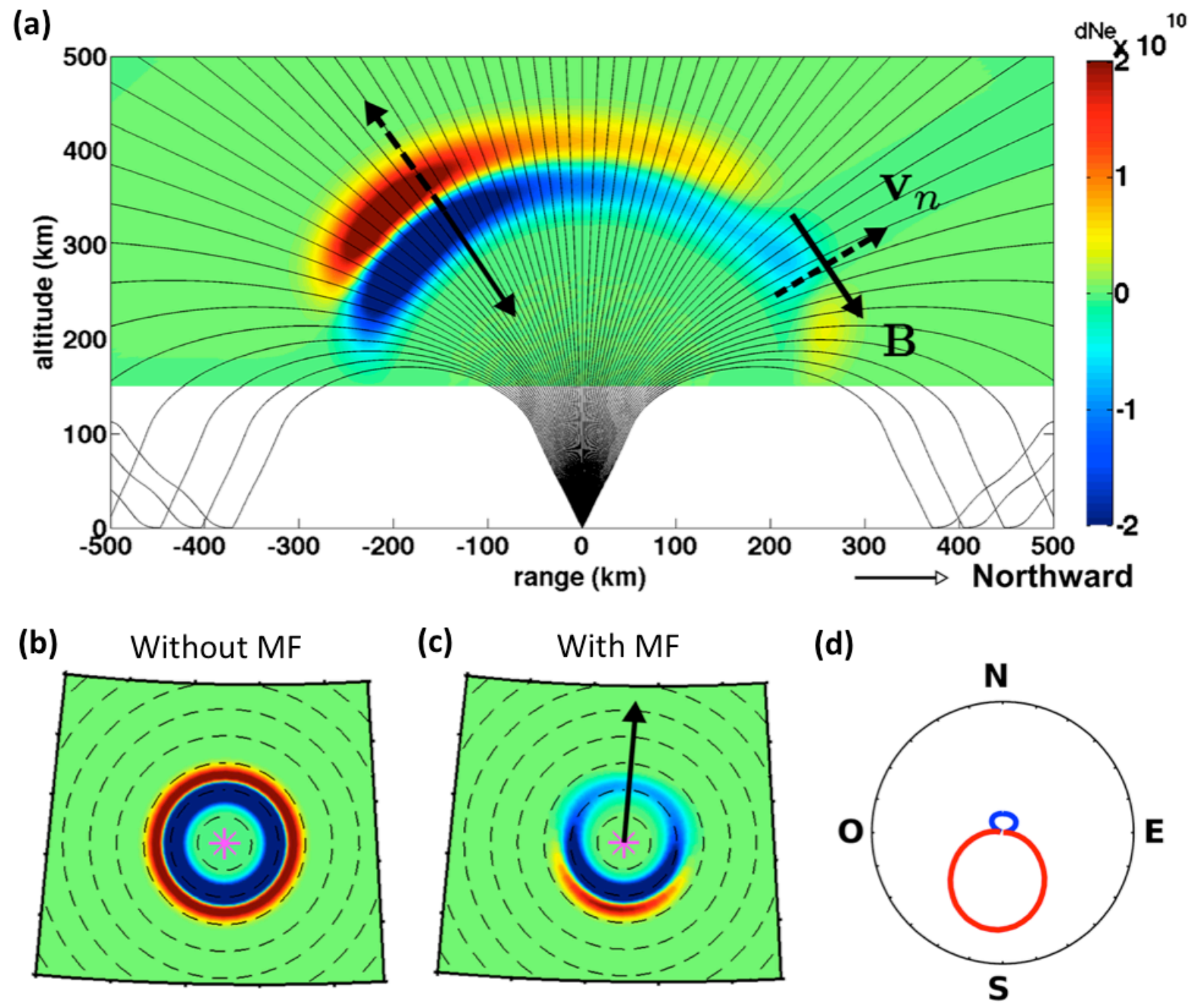

Figure 8. Impact of the geomagnetic field on the evolution of co-seismic ionospheric

1331 disturbances: (a) in vertical plane - electron density perturbation ( $\mathrm{dNe}$ ) 13 minutes after the 1332 earthquake onset time. Solid black arrow indicates the magnetic field vector $\mathbf{B}$, dotted arrow 1333 shows the neutral perturbation velocity; (b-c) in horizontal plane - electron density 1334 perturbation at $280 \mathrm{~km}$ height without (b) and with the geomagnetic field effect (c). The 1335 epicenter is located at the purple star, and the dashed circles show epicentral distance isolines 1336 at $100 \mathrm{~km}$ intervals; (d) Ionospheric radiation pattern, computed at $280 \mathrm{~km}$ height and 200 $1337 \mathrm{~km}$ of epicentral distance. Blue is negative polarity, and red is positive polarity. It should be 1338 noted that this example is valid for the Northern Hemisphere. In the Southern Hemisphere, 1339 the magnetic field will "favor" the northward propagation. [Adapted from Rolland et al., 2013, 1340 modified] 
(a) co-seismic water displacement

1342

1343

1344

1345

1346

1347

1348

1349

1350

1351

1352

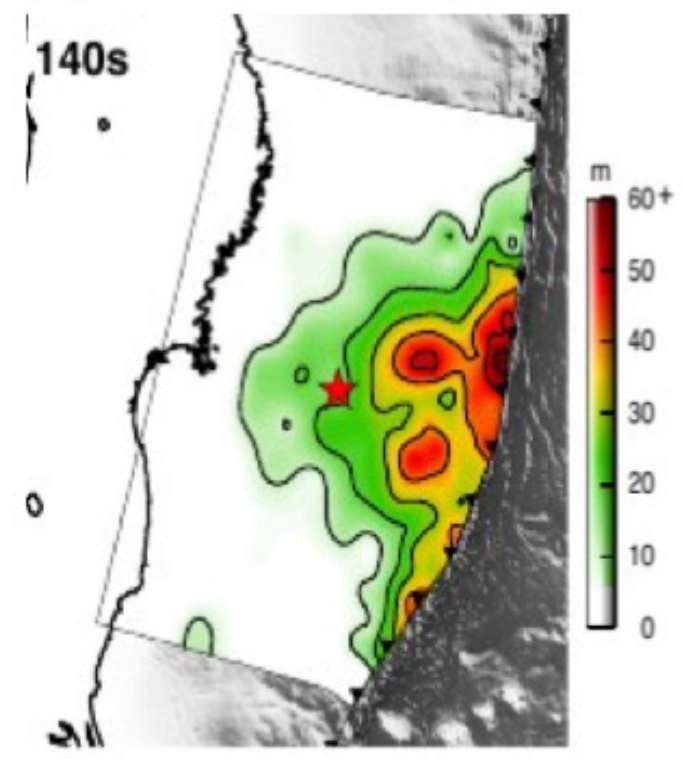

(b) lonospheric «imprint»

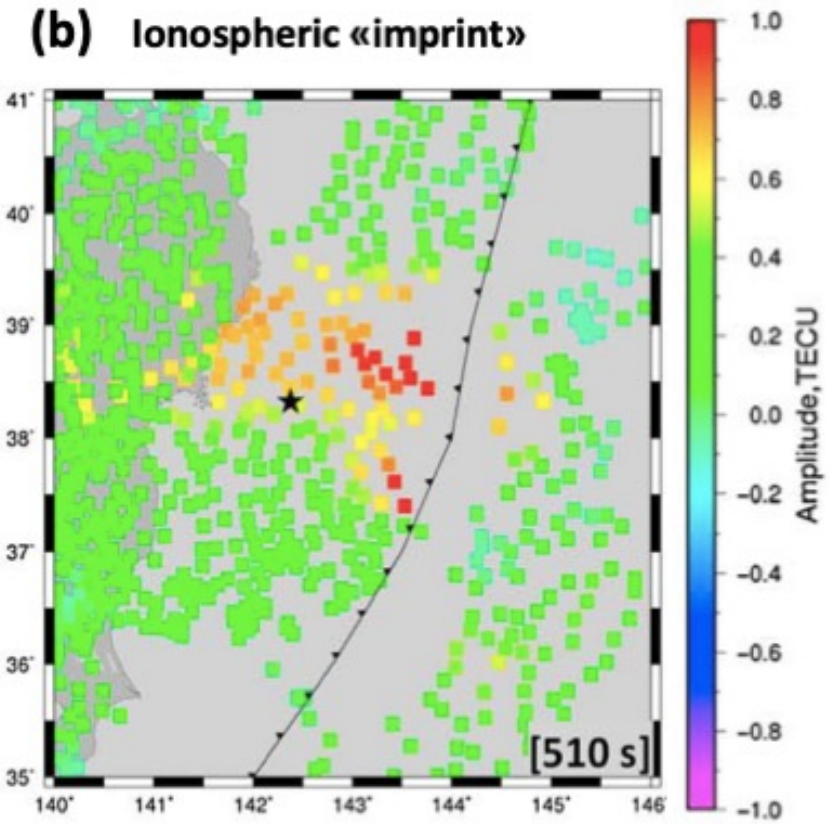

Figure 9. (a) Model of co-seismic displacements of the water column occurred due to the Tohoku-oki earthquake of 11 March 2011. Color shows the amplitude of the coseismic-slip, red star - the epicenter. [From Bletery et al., 2014]; (b) TEC perturbations above the nearepicentral region of the 11 March 2011 Tohoku-oki earthquake, a snapshot at 510 sec after the earthquake. Color indicates the TEC value, and the color scale is shown on the right. Black star indicates the epicenter of the Tohoku-oki earthquake [From Astafyeva et al., 2013b]. 
(a) October 28, 2012 (PRN 8)

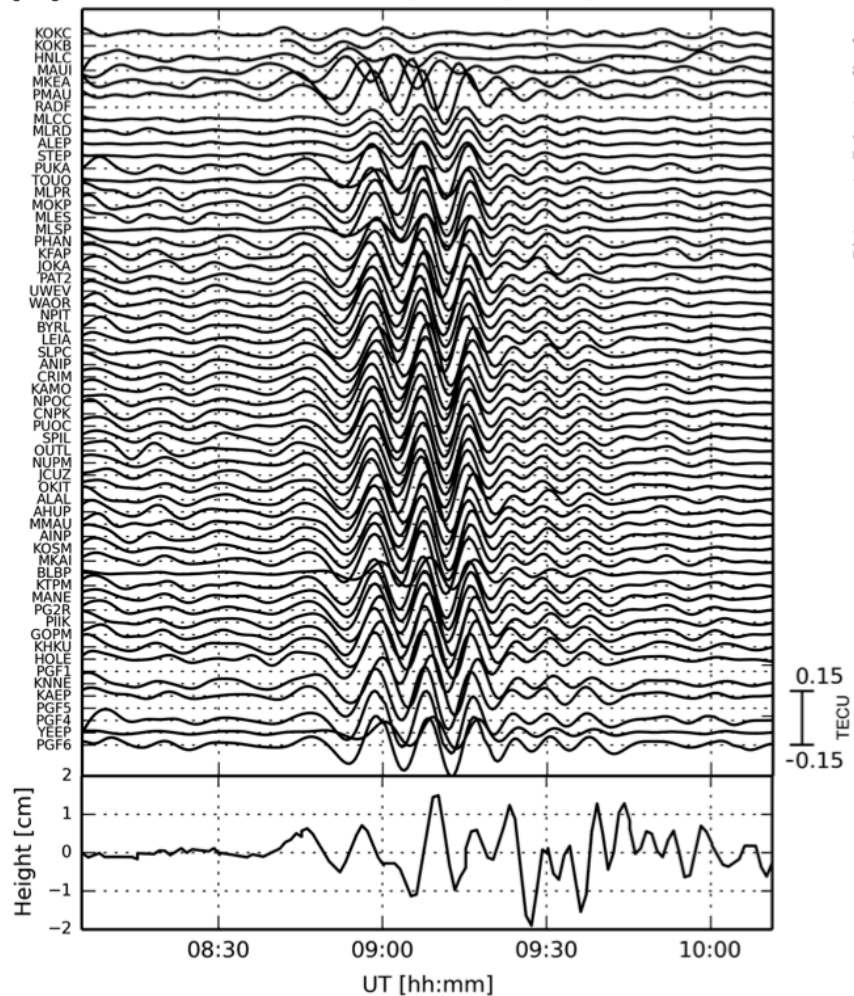

(b)

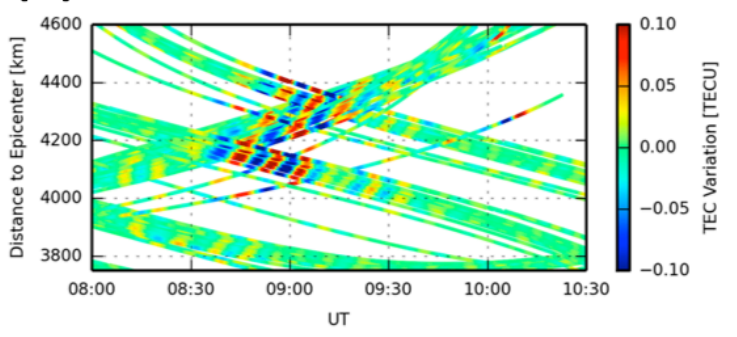

(C) 11-Mar-2011 12:58:01 UT, 1.0-1.7 mHz

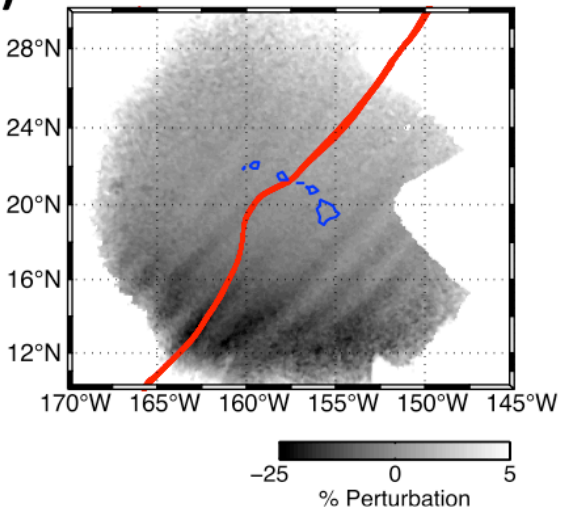

Figure 10. Examples of co-tsunamic ionospheric and atmospheric disturbances: (a)

1355 Ionospheric TEC-response to the propagation of the Haida Gwaii tsunami of 28 October 2012

1356 as measured by GPS-satellite PRN08 (top). Names of GPS-receivers are indicated on the left.

1357 The tsunami was generated by the earthquake with an epicenter near Moresby Island, Canada, 1358 and here was detected over the Hawaii Islands ( $4000 \mathrm{~km}$ away). Comparison of the TEC 1359 with tidal gauge from DART station 51407 (bottom) suggests the tsunami as the origin of the 1360 perturbation. (b) Travel-time diagram showing quasi-periodic TEC oscillations in response to 1361 the Haida Gwaii tsunami propagation in Hawaii. [Panels (a) and (b) are adapted from Grawe 1362 and Makela, 2015]; (c) The 11 March 2011 Tohoku tsunami-driven signatures in $630 \mathrm{~nm}$ 1363 airglow over Hawaii. Images are processed using filtering with passband 0.1-1.7 $\mathrm{mHz}$ to 1364 highlight the 14.2-min period waves. The red line indicates the tsunami location at the time of 1365 the image. [Adapted from Makela et al., 2011] 


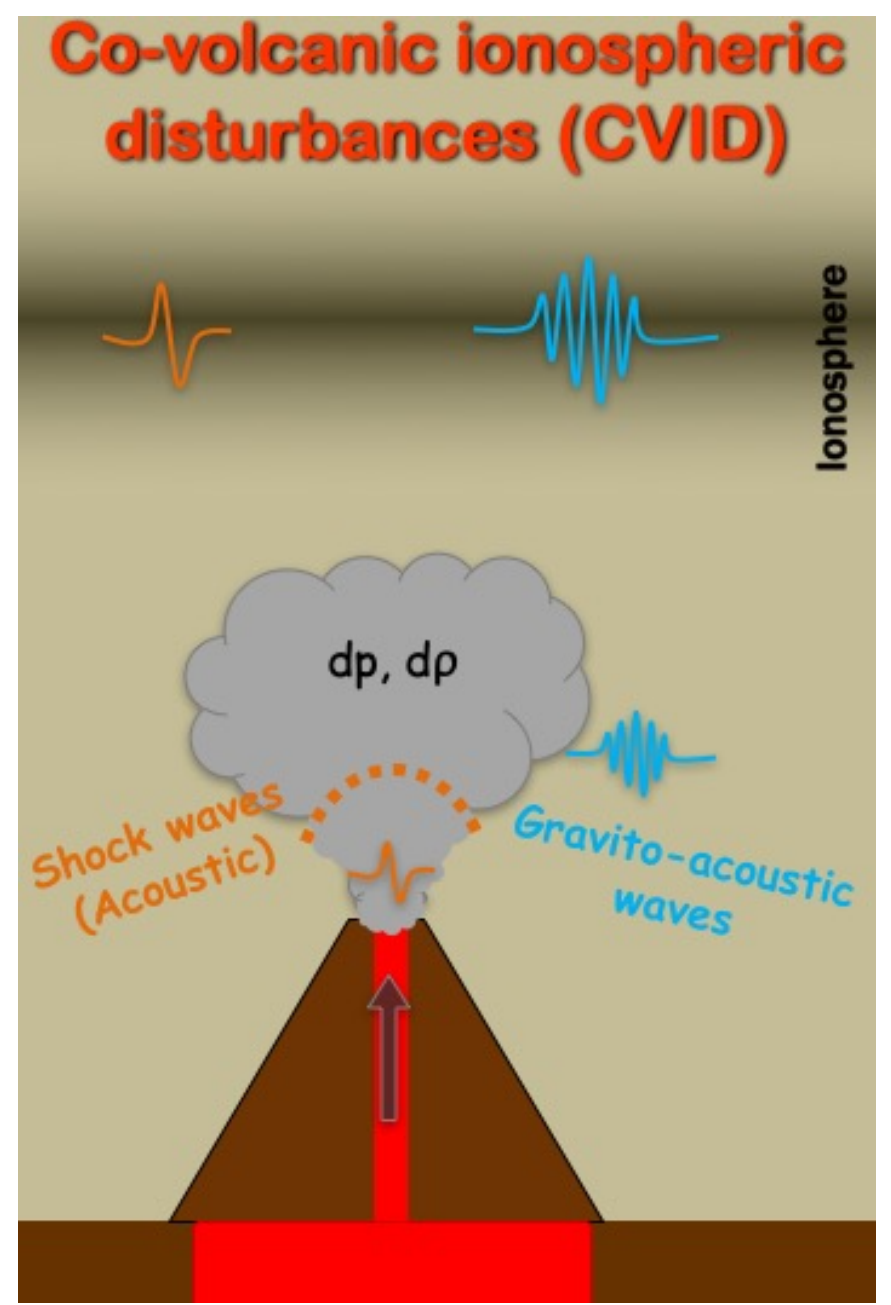
1368 Figure 11. Scheme showing the generation of ionospheric disturbances by a volcanic
1369 eruption. First, shock-acoustic waves may be generated, they arrive in the ionosphere at 1370 starting from $~ 8-9$ min after the beginning of an eruption. Second, with eruption and sudden 1371 changes in the local pressure $(\mathrm{dp})$ and density $(\mathrm{d} \rho)$, gravito-acoustic waves are generated. The 1372 latter waves usually reach the ionospheric altitudes $\sim 45 \mathrm{~min}$ after the eruption. 
(a)

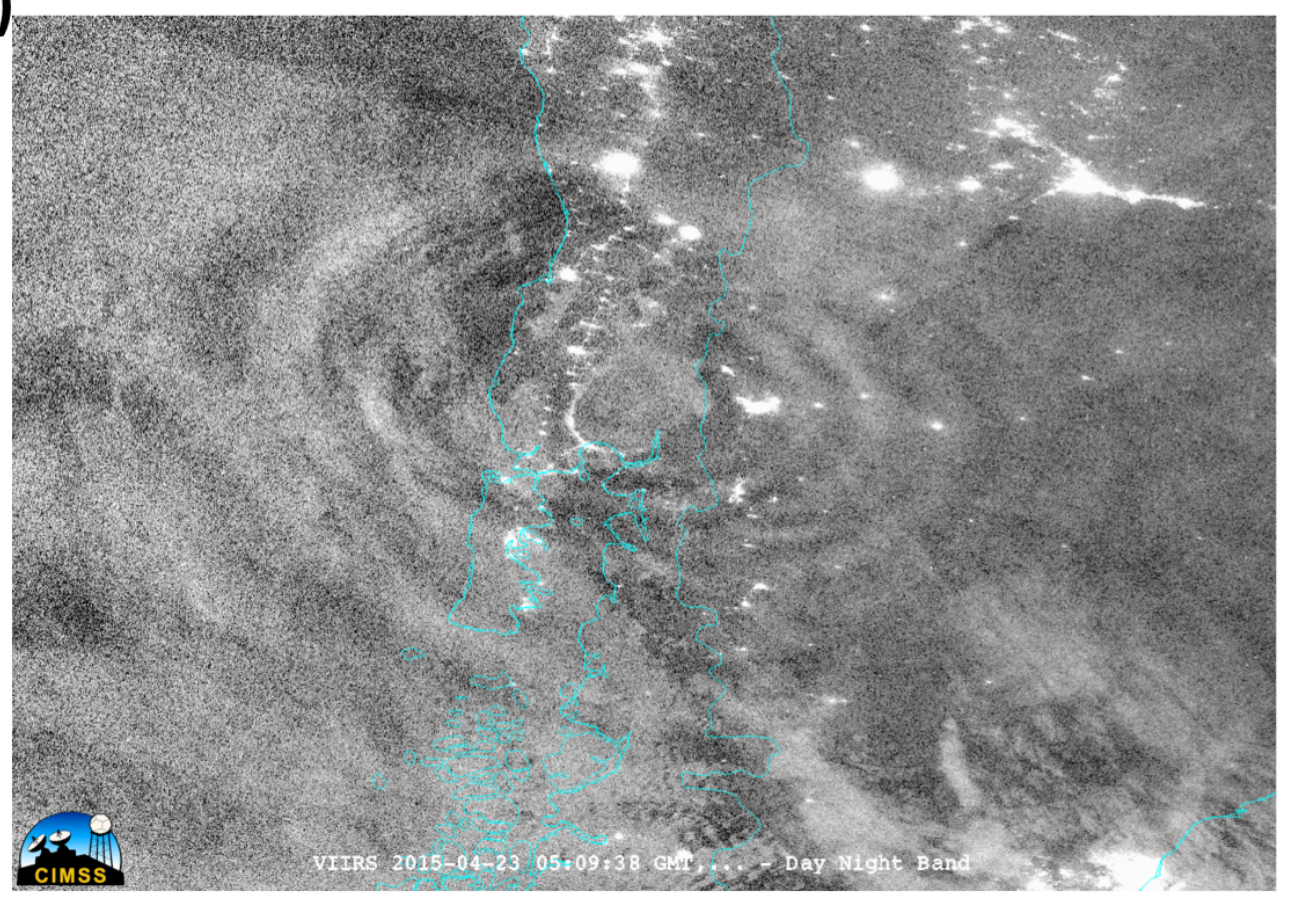

(b)

1375 Figure 12. (a) Mesospheric gravity waves associated with the Calbuco Volcano Eruption of 23 1376 April 2015. The image taken by the Suomi NPP VIIRS Day/Night Band imagery (Miller et al., 1377 2012) at 5:09UT, i.e. one hour after the eruption onset [Image credit: CIMSS, University of 1378 Wisconsin - Madison]; (b) Infrared imagery from VIIRS $11.45 \mu \mathrm{m}$ showing the volcanic plume 1379 drifting north-eastward from the volcano [Image credit: CIMSS, University of Wisconsin 1380 Madison; http://cimss.ssec.wisc.edu/goes/blog/archives/18174]. 


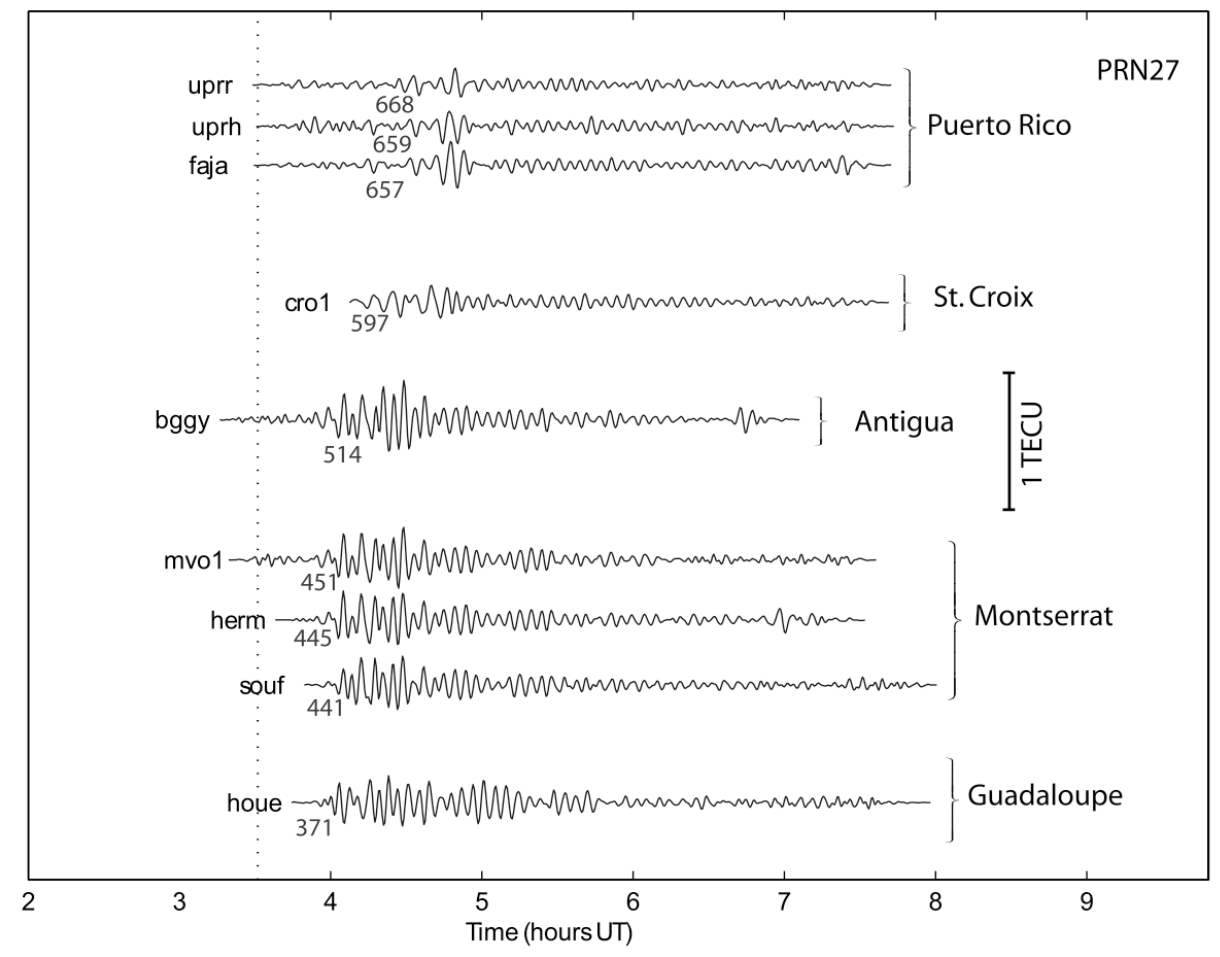

\section{(b) Calbuco eruption \#1}

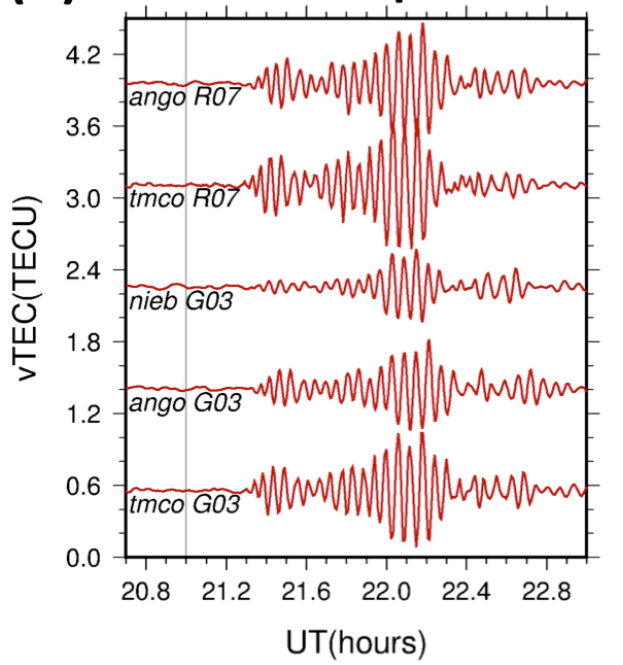

(c) Calbuco eruption \#2

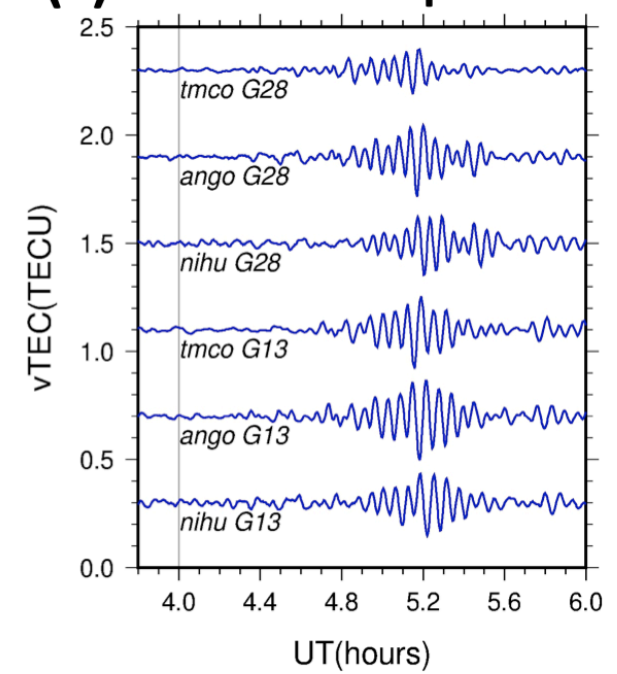

Figure 13. Examples of co-volcanic ionospheric disturbances: (a) TEC response to the Soufrière Hill volcano explosion of 13 July 2003 as registered by GPS-satellite G27 (PRN27). The TEC signals are filtered between 2.2 and $8 \mathrm{mHz}$, the names of GPS-stations are marked on the left of the TEC data series, numbers show the distance in km from the volcano. Vertical dotted line indicates the time of the eruption. [Adapted from Dautermann et al., 2009a]; (b, c) Ionospheric TEC response to the Calbuco volcano eruptions of 22 April 2015 (b) and of 23 April 2015 (c). The vertical gray line shows the first eruption onset at 21:04UT and the second eruption at 4:00UT. Names of GNSS-stations and of GNSS-satellites are shown next to each curve. 

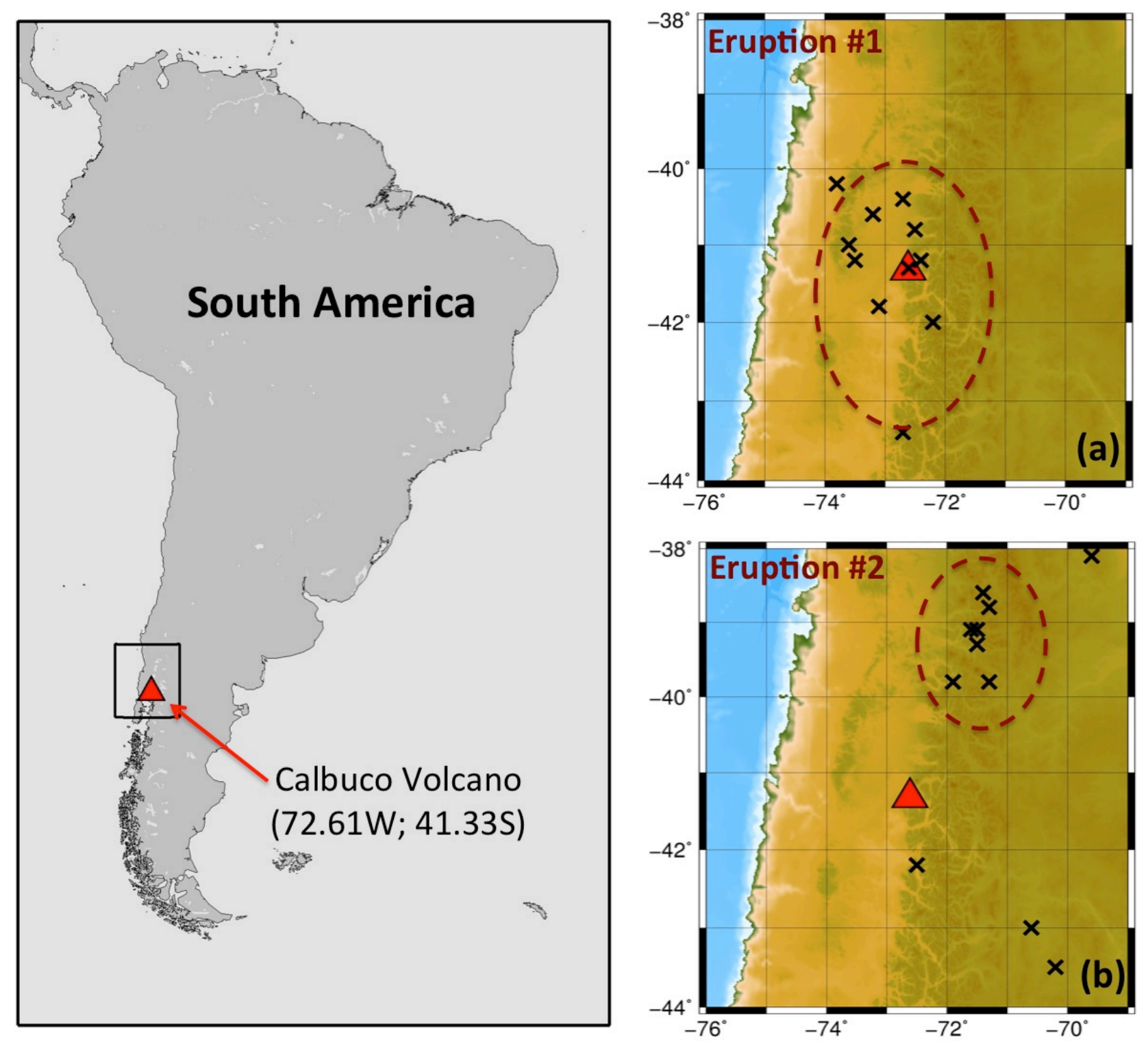

1393 Figure 14. Localization of the eruptions of the Calbuco volcano from the ionosphere: (a) - for 1394 the first eruption of 22 April 2015, (b) - for the second eruption of 23 April 2015. Red triangle 1395 shows the position of the volcano, black crosses - solutions for ionospheric detection of the 1396 eruptions from ionospheric TEC measurements. (The localization results are from Shults et al., 1397 2016). 